Portland State University

PDXScholar

Summer 9-3-2014

\title{
Characterization of Functional Domains of Cul3, an E3 Ubiquitin Ligase, Using Chimeric Analysis
}

Jennifer Anne Mitchell

Portland State University

Follow this and additional works at: https://pdxscholar.library.pdx.edu/open_access_etds

Part of the Biology Commons

Let us know how access to this document benefits you.

\section{Recommended Citation}

Mitchell, Jennifer Anne, "Characterization of Functional Domains of Cul3, an E3 Ubiquitin Ligase, Using Chimeric Analysis" (2014). Dissertations and Theses. Paper 1970.

https://doi.org/10.15760/etd.1969

This Thesis is brought to you for free and open access. It has been accepted for inclusion in Dissertations and Theses by an authorized administrator of PDXScholar. Please contact us if we can make this document more accessible: pdxscholar@pdx.edu. 
Characterization of Functional Domains of Cu13, an E3 Ubiquitin Ligase,

Using Chimeric Analysis

by

Jennifer Anne Mitchell

A thesis submitted in partial fulfillment of the requirements for the degree of

Master of Science

in

Biology

Thesis Committee:

Jeffrey Singer, Chair

Michael Bartlett

Justin Courcelle

Portland State University

2014 


\begin{abstract}
Modification of cellular proteins with molecules of ubiquitin is an important process that regulates the activity of cellular proteins. Cullin RING ligases (CRLs) are multi-subunit complexes that act in concert with E2 enzymes to attach molecules of ubiquitin to protein substrates. There are seven CRLs in mammalian cells (Cul1, Cul2, Cul3, Cul4A, Cul4B, Cul5, and Cul7) that are highly homologous in sequence and structure. CRLs possess a highly conserved C- terminal domain that interacts with E2 enzymes, and a more variable $\mathrm{N}$ - terminal domain which recruits substrates through distinct substrate adapter molecules. Despite the structural similarity, these CRLs recognize distinct substrates and carry out unique functions in cells.

In order to characterize the functional domains of cullins that are responsible for their unique activity, we generated cullin chimeras for expression and analysis in mammalian cells. These chimeras are Cul3 mutants in which the $\mathrm{C}$ - terminal domain or $\mathrm{N}$ - terminal domain of $\mathrm{Cul} 3$ has been replaced by that of $\mathrm{Cul1}$ or Cul2, respectively. These chimeras were cloned into a mammalian expression vector for the purpose of experimentation in cultured cells.

The chimeric cullin constructs provided a valuable tool for investigating how different functional domains of CRLs contribute to their specific functions in cells. In this study, we first investigated if the chimeras that we engineered were able to interact with their respective substrate adapters. We performed co- immunoprecipitation experiments in which we tested the ability of wild type, chimeric, or mutant cullin proteins to bind to three different substrate adapter proteins. We found that the chimera possessing the C-
\end{abstract}


terminus of $\mathrm{Cul} 1$ and the $\mathrm{N}$ - terminus of $\mathrm{Cul} 3$ retains the ability to interact with the BTB substrate adapters Ctb57 and KLHL3. We also found that the chimera that possesses the C- terminus of $\mathrm{Cul3}$ and the $\mathrm{N}$ - terminus of Cull was unable to interact with BTB proteins. Lastly, we found that the Cul1 adapter Skp1 was able to bind to Cul1, but did not bind to $\mathrm{Cul3}$ or either chimera. We concluded that the chimera possessing the Nterminus of Cul3 likely retains the functional binding abilities of $\mathrm{Cul} 3$ at the $\mathrm{N}$ - terminus and would therefore be useful for conducting experiments.

In this study, we also used the cullin chimeras to investigate the binding interactions between E2 enzymes and cullin RING ligases. We performed coimmunoprecipitation assays to examine the interactions between E2 enzymes and wild type, mutant or chimeric cullin proteins. We found that E2 enzyme UbE2E1 selectively binds to Cul3 and not to Cull. Notably, the BTB binding region at the $\mathrm{N}$ - terminus of Cul3 is required for binding to UbE2E1. Furthermore, we found that UbE2E1 also binds to $\mathrm{Cul3}$ substrate adapter protein $\mathrm{Ctb} 57$. These experiments revealed a novel interaction between and E2 enzyme and the $\mathrm{N}$ - terminus of $\mathrm{Cul3}$, as well as with a Cul3 substrate adapter protein. In conclusion, the chimeras generated in this study have provided valuable information regarding what regions of CRLs are important for interactions with other proteins, and will continue to be a useful tool for investigating CRL structure and function. 


\section{TABLE OF CONTENTS}

ABSTRACT

i

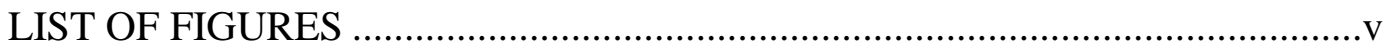

CHAPTER I: INTRODUCTION

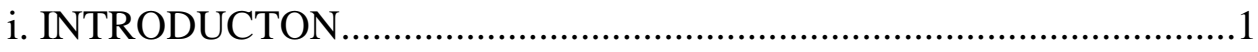

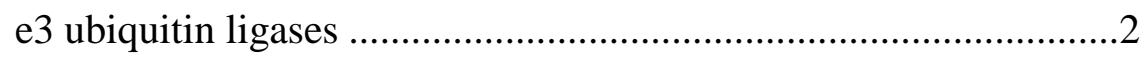

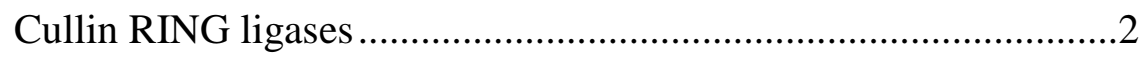

CHAPTER II: DESIGN AND CONSTRUCTION OF CULLIN CHIMERAS

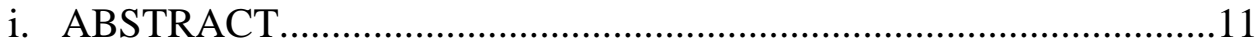

ii. INTRODUCTION …………………............................................

iii. MATERIALS AND METHODS ……………………………........17

Molecular cloning techniques .......................................................17

Site directed mutagenesis ................................................................19

Cell culture, transfections, and western blotting.............................19

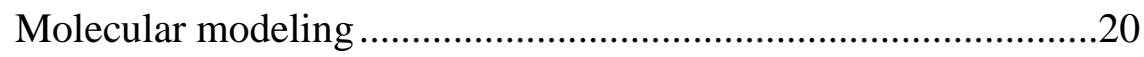

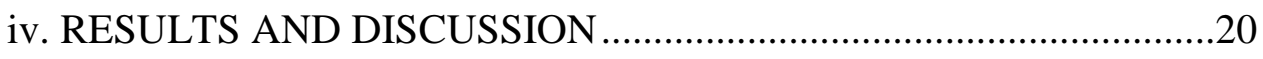

CHAPTER III: EXAMINING SUBSTRATE ADAPTER BINDING OF WILD TYPE AND CHIMERIC CULLINS

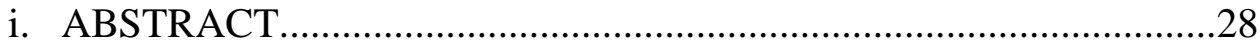

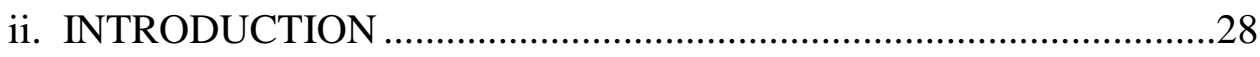

iii. MATERIALS AND METHODS ……………………….....................32

Cell culture, plasmids, and transfections ........................................32

Immunoprecipitation and immunoblotting ......................................32

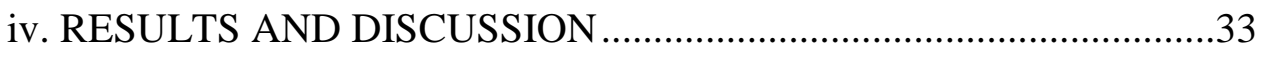

The chimera possessing the $\mathrm{N}$ - terminus of $\mathrm{Cu} 13$ binds BTB adapter proteins 
The adapter protein Skp1 binds to $\mathrm{Cu} 11$, and not to $\mathrm{Cu} 13$ or chimeric CU13 proteins .............................................................35

CHAPTER IV: ANALYSIS OF E2 INTERACTIONS WITH WILD TYPE AND CHIMERIC CULLINS

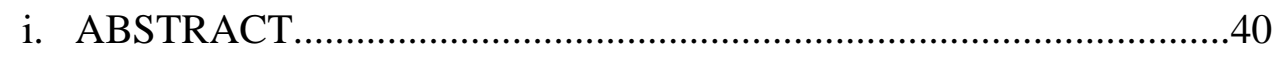

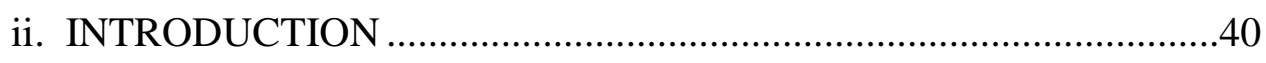

iii. MATERIALS AND METHODS ………………………………….....4

Cell culture, plasmids, and transfections .........................................4

Immunoprecipitation and Immunoblotting .......................................4

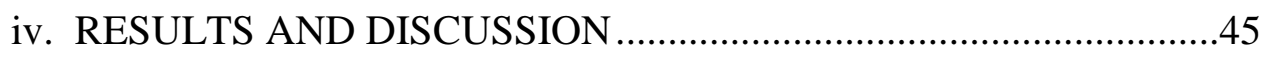

$\mathrm{Cu} 11$ and $\mathrm{Cu} 13$ exhibit differential binding

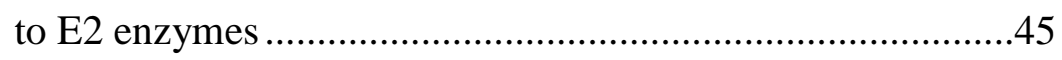

The BTB region of $\mathrm{Cu} 13$ is required for binding

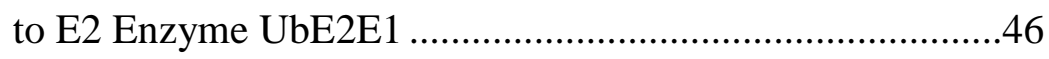

UbE2E1 binds the Cu13 adapter protein Ctb57 ...............................48

CHAPTER V: SIGNIFICANCE AND FUTURE DIRECTIONS

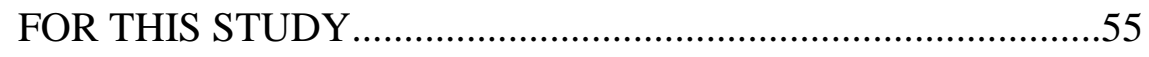

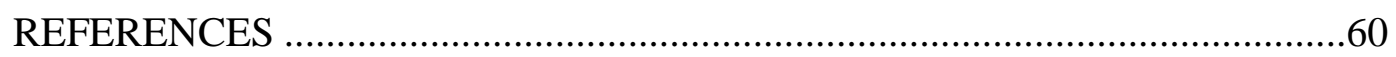




\section{LIST OF FIGURES}

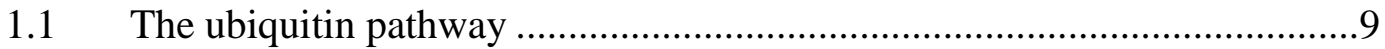

1.2 The modular structure of Cullin RING ligases ....................................10

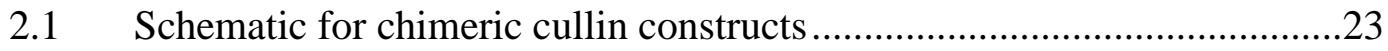

2.2 Chimeric junction placement within the amino acid

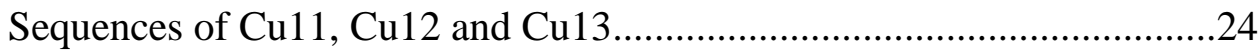

2.3 Cloning strategy for chimeric cullin constructs ...................................25

2.4 Wild type and chimeric cullin expression in HEK 293 cells .....................26

2.5 A molecular model of a chimeric cullin .............................................27

3.1 Wild type and chimeric cullin binding to BTB protein Ctb57..................37

3.2 Wild type and chimeric cullin binding to BTB protein KLHL3 ................38

3.3 Wild type and chimeric culling binding to adapter protein Skp1 .............39

4.1 E2 enzymes UbcH5b, UbcH7, and UbcH10 do not bind

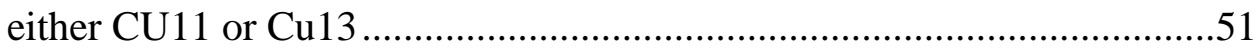

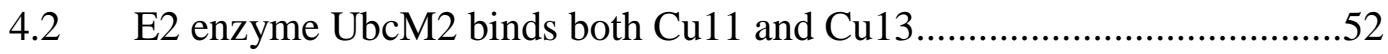


4.3 E2 enzyme UbE2E1 binds $\mathrm{Cu} 13$ and not $\mathrm{Cu} 11$...................................52

4.4 Wild type and chimeric cullin binding to E2 enzyme UbE2E1 ................53

4.5 E2 enzyme UbE2E1 binding to BTB proteins ...................................54

5.1 Models for UbE2E1 interaction with the $\mathrm{Cu} 13$ complex.........................59 


\section{CHAPTER I}

\section{INTRODUCTION}

Post- translational modification of cellular proteins is required for nearly all biological processes in living cells. The covalent attachment of functional groups or small polypeptides to cellular proteins results in an alteration of protein activity, thereby orchestrating numerous biological pathways. There are many examples of posttranslational modifications, including phosphorylation, acetylation, glycosylation, and ubiquitination. These modifications participate in complex signaling networks in living cells. Therefore, understanding how these modifications occur is fundamental to understanding cell biology.

Modification with ubiquitin governs the activity of proteins in cells, much like to phosphorylation. Ubiquitin is a small, highly conserved polypeptide composed of 76 amino acids. Attachment of ubiquitin targets proteins for a variety of fates in cells, notably degradation by the $26 \mathrm{~S}$ proteasome (Ciechanover et al., 1981). During ubiquitin conjugation events, molecules of ubiquitin are attached to targeted substrates by the concerted action of enzymes designated E1, E2, and E3. The ubiquitin activating enzyme, E1, forms an ATP dependent thio-ester bond with a molecule of ubiquitin, which is then transferred to the active site cysteine of an E2 ubiquitin- conjugating enzyme. An E2 then acts in concert with an E3 ubiquitin ligase to covalently attach ubiquitin to lysine residues of substrates (Hershko et al., 1981). This pathway is illustrated in Figure 1.

Attachment of multiple molecules of ubiquitin through repetition of the catalytic cycle results in the assembly of a polyubiquitin chain, which targets the substrate for 
degradation by the $26 \mathrm{~S}$ proteasome (Ciechanover et al., 1981). Alternatively, attachment of a single molecule of ubiquitin also destines proteins for non-degradative outcomes. Examples include membrane protein endocytosis and trafficking, protein kinase activation, and chromatin remodeling (Chen et al., 1996; Chen and Sun, 2009; Hicke, 2001). Thus, ubiquitin modification allows cells to tightly control the timing, abundance, activity, and localization of proteins involved in numerous important pathways.

\section{E3 UBIQUITIN LIGASES}

E3 ubiquitin ligases are responsible for the recognition and recruitment of substrates for ubiquitin modification. Since E3 ligases confer substrate specificity, they play a central role in regulating proteins and thus are an important coordinator of many biological processes. E3 ligases fall into two broad categories: HECT- type E3's (homologous to E6-AP C-terminus) which possess catalytic activity and directly bind molecules of ubiquitin prior to conjugation to substrate, and RING- type E3's (ㄹeallyInteresting- New- Gene) which contain a RING-finger domain and serve as molecular scaffolds, positioning protein substrate in proximity to E2 enzymes for ubiquitin transfer. Our laboratory studies members of a family of RING-type E3s known as the Cullin RING ligases (CRLs). Three important CRLs used in this study are introduced here.

\section{CULLIN RING LIGASES (CRLS)}

CRLs are multi-subunit complexes that assemble in a modular fashion around a central cullin core. There are at least seven cullins in humans (Cul1, Cul2, Cul3, Cul4A, Cul4B, Cul5, and Cul7) that are thought to be highly similar in architecture (Feldman et al., 1997; Kipreos et al., 1996; Mathias et al., 1996). Cullin complexes act as a molecular 
scaffold, recruiting and positioning substrates into close proximity of E2 enzymes for ubiquitin conjugation. The most well-characterized cullin complex is the SCF complex (Skp-1/ Cul1/ F-box), which has been extensively studied for its role in regulation of cell cycle proteins. The SCF complex has been shown to regulate cyclins D and E, as well as the cyclin dependent kinase inhibitors p27 and p21 (Ganoth et al., 2001; Kipreos et al., 1996; Yu et al., 1998). Thus, the SCF complex is an important regulator of the G1-S transition and cell cycle progression.

Crystallographic analysis into the structure of the SCF complex revealed that the complex consists of multiple subunits assembled around a central cullin protein (Cul1). The globular C- terminal region of Cull binds the RING domain protein Rbx1, which serves as a docking site for ubiquitin- activated E2. The N- terminal region of Cull binds the adaptor protein Skp1, which interacts with F-box proteins bearing protein interaction domains responsible for the recognition of substrate (Zheng et al., 2002). The SCF complex was among the earliest CRL complexes to be characterized, and has since served as a model for the structure of cullin complexes.

Another well- characterized cullin complex is the ECS complex (Elongin$\mathrm{C} / \mathrm{Cul} 2 / \mathrm{SOCS}$ box), which has been well characterized for its role in the human genetic disorder von Hippel-Lindau syndrome. ECS targets a host of unique protein substrates for degradation, including the transcription factor hypoxia inducible factor $1 \alpha(\operatorname{HIF} \alpha)$. VonHippel-Lindau syndrome results from mutations in the gene which codes for the Cul2 substrate adapter protein VHL. Mutations in VHL interrupts the ability of the complex to target HIF $\alpha$ for degradation, leading to a buildup of this transcription factor and 
predisposing individuals to the formation of tumors (Maher and Kaelin, 1997). Like the SCF complex, VHL/Cul2 also assembles into a multi-subunit complex, binding Rbx 1 and an ubiquitin activated E2 at its C- terminus, while interacting with substrates at its Nterminus via the adapter proteins Elongin B /C and the substrate adapter VHL (Pause et al., 1997).

A more- recently discovered cullin family member, Cul3, appears to share a similar structure and is currently being characterized by our laboratory and others. Since its discovery, Cul3 has been shown to recognize and recruit a growing number of diverse substrates in mammalian cells. Our laboratory has demonstrated that $\mathrm{Cul} 3$ is required for normal development in mouse embryos, as the loss of Cul3 leads to early embryonic arrest (Singer et al., 1999). Cul3 plays a role in many fundamental processes, as it has been shown to regulate such diverse substrates as the microtubule severing protein p60/ katanin, transcription factor Nrf2, and meiotic spindle- formation factor Meil (Cummings et al., 2009; Pintard et al., 2003; Zhang et al., 2004). We have also shown that Cul3 is required for the degradation of cyclin $\mathrm{E}$, and thus is another important player in cell cycle regulation (Singer et al., 1999), (McEvoy et al., 2007).

A growing body of evidence suggests that all CRLs share a similar modular architecture consisting of three distinct functional domains: an $\mathrm{N}$-terminal domain which binds adaptor proteins responsible for substrate recognition and recruitment, a stalk- like central domain, and a highly conserved globular C-terminal domain known as the cullin domain (Pause et al., 1999; Pintard et al., 2004; Willems et al., 2004). A conserved site in the cullin domain binds the RING domain protein Rbx1 (also referred to as Hrt1, Rub1, 
or Roc1), which serves as a docking site for ubiquitin activated E2 enzymes (Kamura et al., 1999; Ohta et al., 1999; Seol et al., 1999; Tan et al., 1999).

The C- termini of CRLs are also modified with a molecule of NEDD-8 (Neural precursor cell Expressed Developmentally Down-regulated protein $\underline{8}$ ). NEDD-8 is a small, ubiquitin like molecule that is covalently attached to a conserved lysine residue in the cullin domain of CRLs. Neddylation is thought to be required for CRL activation and ubiquitylation activity, presumably by inducing a conformational change in the RING domain which positions the E2 in closer proximity to substrate for ubiquitin transfer (Hori et al., 1999; Ohh et al., 2002; Pan et al., 2004).

While the C- terminal domain of cullins is highly conserved, the $\mathrm{N}$ - terminus is more variable and interacts with protein substrates via different, but related modules. Cul1 interacts with substrates through adaptor Skp1, which binds separate protein recognition subunits called F-box proteins. Cul2 binds the adapter Elongin C, which interacts with substrate via separate SOCS box proteins (Stebbins et al., 1999). Cul3 recognizes substrates through a single adaptor protein that binds to $\mathrm{Cul3}$ via a $\mathrm{BTB}$ domain (Bric a Brac, Tramtrack, and Broad- complex) and recognizes substrates through various protein-protein interaction motifs such as Kelch, Zinc Finger, or MATH domains (Stogios et al., 2005). The modular assembly of these three cullin complexes is illustrated in Figure 1.2.

While Cul1, Cul2, and Cul3 complexes are highly similar in structure, they target distinct substrates and thus perform unique functions in cells. The work described in this thesis aimed to characterize the regions of $\mathrm{Cul} 3$ that are responsible for its specific 
functions in mammalian cells. Toward this goal, we created Cul3 mutants in which the Cterminal region and $\mathrm{N}$ - terminal region of $\mathrm{Cul3}$ has been replaced by that of Cul1 or Cul2, respectively. This was achieved by using molecular cloning techniques to swap out the coding regions of Cul3 DNA which correspond to the $\mathrm{C}$ - terminal and $\mathrm{N}$ - terminal region of the Cul3 protein with that of Cul1 or Cul2. These cullin chimeras were cloned into a mammalian expression vector, which allowed us to express these chimeric proteins in cultured cells, and perform experiments to characterize the binding interactions and activity of the chimeras in cells. The information gained from these experiments has provided valuable insight into which regions of the Cul3 protein are essential for its unique interactions and functions.

The cullin chimeras have provided a direct approach to addressing specific questions regarding CRL complex assembly. For example, the model suggests that the homologous $\mathrm{C}$ - termini of $\mathrm{Cul1}$, Cul2, and $\mathrm{Cul3}$ bind the RING protein Rbx1, which serves as a docking site for ubiquitin- activated E2 enzymes. E2 enzymes then work in concert with CRLs to attach molecules of ubiquitin to substrates.

While 38 E2 enzymes have been identified in humans, little is known about how specific E2s are recruited to CRLs. Given that the cullin domain is highly conserved, and all cullins bind Rbx in a similar way, then how do certain E2s bind one CRL and not another? What structural features of different cullins are required for interactions with different E2 enzymes?

It has been suggested that E2 enzymes are responsible for selecting which lysine residues of substrates are ubiquitinated, as well as for the type of ubiquitin chains that are 
attached to substrates (Jin et al., 2008; Kim et al., 2007). Since both the placement and branching of ubiquitin chains play a major role in the fates of substrates, the interactions between CRL complexes and E2s are very important for understanding cullin specific functions in vivo.

The chimeric approach has allowed us to test the current model of CRL complex assembly, and directly address the important questions posed above. For example, in order to characterize what part of CRL complexes are required for binding to E2 enzymes, we cotransfected wild type and chimeric cullins with several different E2 enzymes in cultured cells. Immunoprecipitation experiments revealed novel interactions between cullins and E2s, and also contributed important information regarding which regions of cullins are participating in these E2 interactions.

Beyond characterizing binding interactions, the chimeric cullins will also be used to investigate Cul3 specific functions in vivo. The ultimate goal for the chimeras generated in this study is to perform complementation assays to determine if the chimeras are capable of performing Cul3 specific functions in cultured cells. At the time of this writing, these experiments have not yet been carried out, but represent an important future goal for this work.

For the complementation assays, we possess a conditional knock out of the Cul3 gene in mouse embryonic fibroblasts (MEFs), wherein the addition of drug to these cell lines results in the deletion of Cul3. Since we have shown that the deletion of Cul3 in mice results in early embryonic arrest, deletion of $\mathrm{Cul} 3$ in cultured cells is expected to have certain observable phenotypes. Therefore, complementation experiments can be 
performed in which each chimera is introduced separately into MEFs, after which endogenous Cul3 will be deleted. These cell lines will then be analyzed to determine if chimera expression was able to rescue the phenotypes associated with the loss of Cul3. Thus, these experiments will allow us to begin to characterize what regions of $\mathrm{Cul} 3$ are required for $\mathrm{Cul} 3$ specific functions.

The work described in this thesis addresses important questions regarding CRL complex assembly and function in mammalian cells, and is organized into five chapters. The design and construction of the cullin chimeras are discussed in detail in Chapter II. The binding of wild type and chimeric cullin proteins to substrate adapters in cullin complexes is examined in Chapter III. Wild type and chimeric cullin binding to E2 enzymes is discussed in Chapter IV. Finally, the significance and future directions for this study are discussed in Chapter V. 


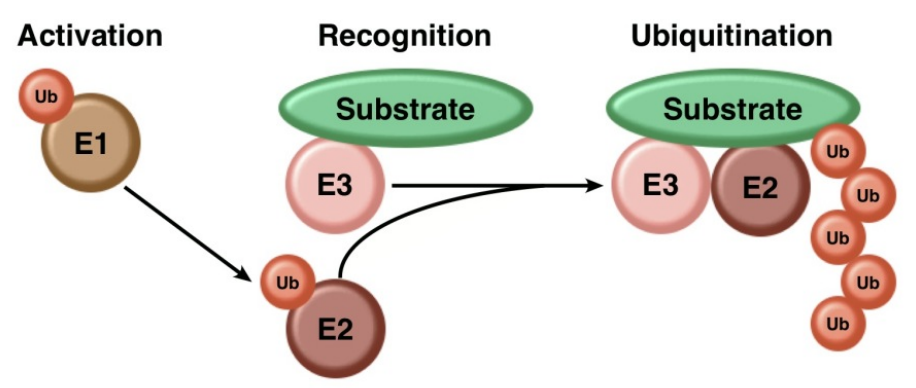

Figure 1.1: The Ubiquitin Pathway

Ubiquitin is attached to protein substrates by the concerted action of enzymes E1, E2, and E3. The ubiquitin activating enzyme E1 forms a high energy bond with a molecule of ubiquitin, and transfers the ubiquitin to the active site of an ubiquitin conjugating enzyme E2. The E2 enzyme then works in concert with an E3 ubiquitin ligase to attach molecules of ubiquitin to lysine residues of protein substrates. Repetition of this catalytic cycle can result in the assembly of a polyubiquitin chain, which targets the substrate for degradation by the $26 \mathrm{~S}$ proteasome. 

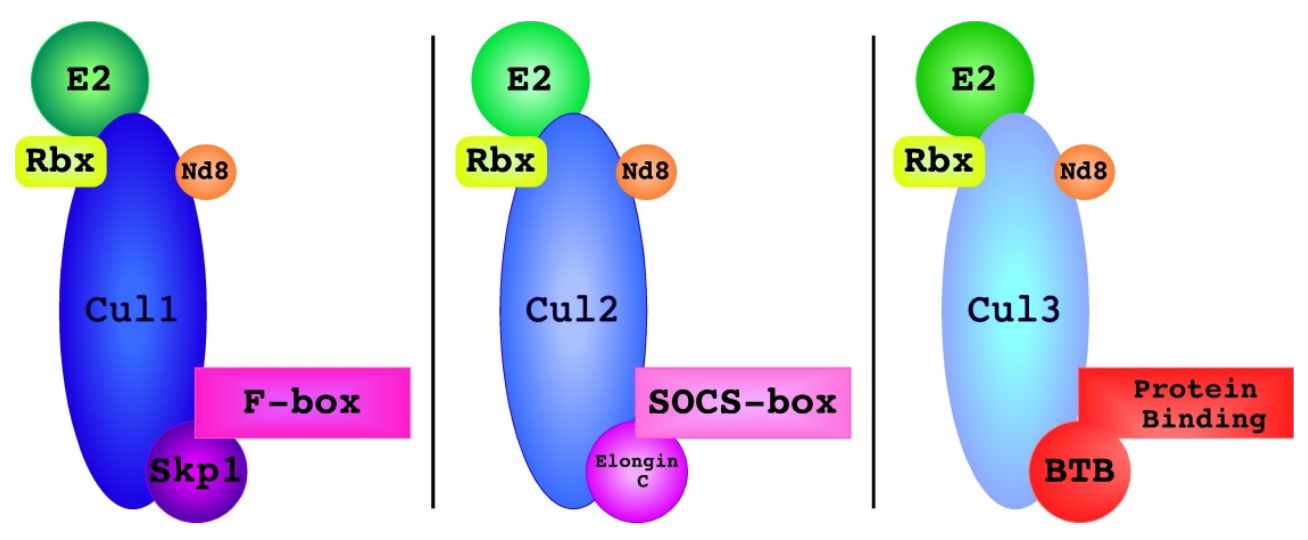

\section{Figure 1.2: The modular structure of Cullin Ring Ligases}

Cullin ring ligases Cul1, Cul2, and Cul3 assemble into multisubunit complexes that are structurally similar. The C- termini of these cullins are highly homologous, and bind the RING domain protein Rbx1, which serves as a docking site for ubiquitin conjugated E2 enzymes. A conserved lysine residue at the C- termini of cullin complexes is modified with a molecule of Nedd- 8, which is thought to activate cullin complexes by inducing a conformational change in the cullin protein which positions the E2 in closer proximity to substrate for ubiquitin transfer. The N-terminal regions of these cullins are more variable and interact with protein substrates via distinct protein modules. Cull interacts with substrate through the adapter protein Skp1 and substrate binding subunits known as F- box proteins. Cul2 recruits substrates through the adapter Elongin $\mathrm{C}$ and substrate binding SOCS- box proteins. While Cul1 and Cul2 bind substrates via two separate subunits, Cul3 interacts with substrates via a single polypeptide, which binds to Cul3 though a BTB domain and interacts with substrates via variable protein interaction motifs. 


\title{
CHAPTER II
}

\section{GENERATION AND EXPRESSION OF CHIMERIC CUL3 PROTEINS}

\begin{abstract}
Cul1, Cul2, and Cul3 are three closely related cullin RING ligases (CRLs) that act in concert with E2 enzymes to attach molecules of ubiquitin to protein substrates. These CRLs possess a highly conserved C- terminal domain that interacts with E2 enzymes, and a more variable $\mathrm{N}$ - terminal domain which recruits substrates through distinct substrate adapter molecules. Despite the structural similarity, these CRLs recognize distinct substrates and carry out unique functions in cells. In order to characterize the functional domains of Cul3, we generated cullin chimeras for expression and analysis in mammalian cells. These chimeras are Cul3 mutants in which the $\mathrm{C}$ - terminal domain or $\mathrm{N}$ - terminal domain of Cul3 has been replaced by that of $\mathrm{Cul} 1$ or Cul2, respectively. These chimeras were cloned into a mammalian expression vector for the purpose of experimentation in cultured cells. All of the plasmids were sequenced and it was confirmed that the inserts were correct and in frame. The plasmids were transfected into cultured cells, and western blotting was used to visualize the expression of chimeric cullin protein. The chimeras all appeared to be modified with Nedd-8, which suggested that the chimeras are likely folded into the proper confirmation. Here the design and construction of the chimeras are discussed in detail.
\end{abstract}

\section{INTRODUCTION}

Chimeric analysis is extremely valuable for investigating the structure and function of homologous members of protein families. Since members of protein families 
are often descendants from a single gene that has undergone duplications, homologues within the same family frequently have similar structure yet divergent functions. Thus, the generation of a chimeric protein where similar structural domains can be swapped is a valuable tool for investigating the divergent roles of closely related proteins.

Classical examples of chimeric analysis can be seen in studies involving nuclear hormone receptors. The nuclear hormone receptors are members of a protein superfamily which regulate transcription in response to binding of hormone ligands. These proteins are essentially made up of two main domains: a ligand binding domain and a DNA binding domain. Each receptor binds to specific DNA sequences and activates transcription of certain genes in response to binding of hormone molecules. Swapping out different DNA binding or ligand binding domains among different nuclear hormone receptors using chimeric cloning techniques provided many researchers with a systematic way to examine the roles of these functional domains in different receptors in cells.

The experiments described in this thesis used chimeric analysis to characterize the functional domains of $\mathrm{Cul} 3$, an important member of the cullin family of E3 ligases. As described in Chapter I, the current model for cullin complex assembly suggests that cullins consist of three main domains: an $\mathrm{N}$ - terminal domain that recruits substrate, a stalk like central domain, and a globular C- terminal domain. The chimeric cullins constructs generated in this study code for Cul3 fusion proteins in which the N-terminal (substrate recognition) region or C- terminal (E2 binding) regions have been replaced by that of Cul1 or Cul2, respectively. These cullin chimeras were created in a mammalian expression vector, allowing us to express these chimeric proteins in cultured cells, and 
perform experiments to characterize the structural features of different cullins that make their activity unique.

In this chapter, the design and construction of the chimeric cullin constructs is described in detail. Four chimeras were generated: Two chimeras that are essentially Cul3 with the N- terminus of Cul1 or Cul2 respectively (named Cul1 NTD and Cul2 NTD); and two chimeras that are Cul3 with the C- terminus of Cul1 or Cul2 respectively (named Cul1 CTD and Cul2 CTD). A schematic illustrating these chimeric cullins can be seen in Figure 2.1.

\section{DESIGN AND CONSTRUCTION OF CULLIN CHIMERAS}

The first step in the design of the chimeras was to clearly define the $\mathrm{N}$ - terminal and $\mathrm{C}$ - terminal domains in the amino acid sequences of $\mathrm{Cul1}$, Cul2, and Cul3. For the Nterminus, this was achieved by searching through published data for what is known about which amino acids appear to be required for each cullin to bind their respective substrate adapters. While the $\mathrm{N}$ - termini of different cullins are variable, they all possess a similar motif consisting of three repeats each made up of a five helix bundle, which is termed the cullin repeat. Studies performed on the SCF complex determined that the interaction between Cull and Skp1 resides in helix one within most $\mathrm{N}$ terminal repeat, which consists of approximately 120 amino acids (Zheng et al., 2002) . For the Cul2 complex, a study using deletion mutants suggested that $\mathrm{Cul} 2$ binding to Elongin $\mathrm{C}$ requires the first 158 amino acids (Pause et al., 1999). Finally, several studies using deletion mutants have suggested that the amino acids required for Cul3 binding to BTB proteins reside on helix 2 and helix 5 of the most N- terminal cullin repeat (Pintard et al., 2004; Pintard et al., 
2003; Xu et al., 2003). Therefore, in the design of the chimeric constructs, we made certain that the $\mathrm{N}$ - terminal domains to be swapped each encompassed the residues required for interaction with their respective substrate adapters.

The C- terminal domains of $\mathrm{Cul1}, \mathrm{Cul} 2$, and $\mathrm{Cul} 3$ were defined by entering the amino acid sequences for each cullin into the NCBI conserved domain search tool. As described in Chapter I, the C- terminus of cullins possesses a highly conserved globular domain referred to as the cullin domain. Encompassing a stretch of approximately 150 amino acids, the cullin domain is required for interaction with RING domain proteins such as Rbx1 (Ohta et al., 1999).

Therefore, in the design of the $\mathrm{C}$ - terminal chimeras, we made certain that the defined C- terminal regions for each cullin encompassed the stretch of amino acids identified as the cullin domain by the NCBI conserved domain search tool. It should also be noted that the neddylation site for all three of these cullins lies downstream of the cullin domain. Thus, the defined C- terminal domain for each cullin also encompassed the site of Nedd-8 modification.

Once the $\mathrm{N}$ - terminal and $\mathrm{C}$ - terminal regions of $\mathrm{Cul1}, \mathrm{Cul} 2$, and $\mathrm{Cul} 3$ were clearly defined, we then used protein alignment software to determine where to place the chimeric junctions within the protein sequences of each cullin. We wanted to create the junctions within a stretch of amino acid sequence that is relatively conserved between the three cullins, so that the changes made to the amino acid sequence in that area would be minimal and unlikely to disturb the way in which the chimeric protein folds. Therefore, we performed an alignment on Cul1, Cul2, and Cul3 amino acid sequences using 
CLUSTALW software. The placement of the chimeric junctions was chosen in areas of relatively high homology between the three cullins, and also such that each junction separated the predefined $\mathrm{N}$ - terminal and $\mathrm{C}$ - terminal regions for each cullin. The amino acid alignment and the placement of the chimeric junctions are shown in Figure 2.2.

Once the $\mathrm{N}$ - terminal and $\mathrm{C}$ - terminal regions were defined and the placement of the junctions in the cDNA determined, the next step was to use molecular cloning techniques to generate the chimeric constructs. The cloning strategy is illustrated in Figure 2.3 and is also described here:

First, wild type Cul3 cDNA was cloned into the mammalian expression vector used in this study. The cloning was carried out by use of PCR that generated the coding region of the human Cul3 gene flanked by two unique restriction sites at the 5' and 3' ends, respectively. These restriction sites were chosen so that restriction digests could later be used to swap out the 5' and 3' regions of Cul3 cDNA that correspond to the Nterminal and $\mathrm{C}$ - terminal regions of the $\mathrm{Cul} 3$ protein, respectively.

The chimeric constructs containing the $\mathrm{N}$ - terminal regions of either Cul1 or Cul2 were created by utilizing a third unique restriction site located approximately 300 base pairs into the coding region of Cul3. A restriction site at this location was chosen because it would allow us to use restriction digests to cut out and replace the coding region that corresponds the $\mathrm{N}$ - terminus of Cul3. To create the $\mathrm{N}$ - terminal Cul3 chimeras, DNA fragments corresponding to the $\mathrm{N}$ - terminal regions of Cul1 or Cul2 were generated by PCR, flanked by the same two restriction sites that flank the $\mathrm{N}$-terminal region in the wild type Cul3 plasmid. Restriction digests and ligations were then carried out resulting in 
constructs coding for two chimeric cullins: Cul3 mutants with the N-terminal region replaced by that of Cull or Cul2, respectively.

The Cul3 chimeras that contain the C-terminal regions of either $\mathrm{Cul1}$ or $\mathrm{Cul} 2$ were created similarly, with one notable difference. In the wild type Cul3 plasmid, there was not a unique restriction site upstream of the C-terminal region that we wished to replace. Therefore, we created an additional unique restriction site using site directed mutagenesis. PCR reactions were then performed to generate C-terminal fragments of Cul1 and Cul2 also flanked by the same two restriction sites that flank the C-terminal region in the wild type $\mathrm{Cul} 3$ plasmid. Subsequent restriction digests and ligation reactions resulted in constructs coding for two additional chimeras: Cul3 mutants with the Cterminal region replaced by that of Cul1 or Cul2 respectively.

The chimeric constructs were sequenced, to verify that the $\mathrm{N}$ - terminus and $\mathrm{C}$ terminus of Cul3 had indeed been replaced by that of Cul1 or Cul2. The sequencing data confirmed that the chimeric junctions were created as intended. The constructs were then separately transfected into cultured HEK 293 cells, to verify that the plasmids were able to express chimeric cullin proteins in cells. Importantly, the plasmids were all capable of expressing chimeric protein in cultured cells, providing us with a valuable experimental tool for investigating CRL structure and function. Lastly, all four chimeras appear to be modified with Nedd-8, indicating that they are likely properly folded. 


\section{MATERIALS AND METHODS}

\section{Molecular cloning techniques}

Standard molecular techniques were used to clone wild type and chimeric cullins into the mammalian expression vector pCMV-3Tag-6. The templates and primers used for PCR are provided here, as well the enzymes used for restriction digests.

PCR was used to generate wild type human Cul1, Cul2, and Cul3 coding regions using pcDNA templates. The primers used were designed to produce PCR product flanked by restriction sites for cloning into the pCMV-3Tag6 vector. Thus, the restriction sites flanking the wild type cullin coding regions in pCMV-3Tag-6 are as follows: Cull is flanked by Srf1 and BamHI, and Cul2 and Cul3 are both flanked by SrfI and ClaI.

The following primer sequences were used for wild- type cullin PCR :

Cul1 forward primer: 5'CAC TTG GCC CGG GCA ATG TCG TCA ACC CGG AGC 3'

Cul1 reverse primer: 5' CAC GTT GGA TCC TTA AGC CAA GTA ACT GTA GGT GTC C- 3'

Cul2 forward primer: 5' CAC TTG GCC CGG GCA ATG TCT TTG AAA CCA AGA3'

Cul2 reverse primer: 5'- CAC GTT ATC GAT TCA CGC GAC GTA GCT GTA- 3'

Cul3 forward primer: 5' CAC TTG GCC CGG GCA ATG TCG AAT CTG AGC AAA3'

Cul3 reverse primer: 5' CAC GTT ATC GAT TTA AGC CAA GTA ACT GTA GGT GTC C-3' 
FLAG- tagged chimeric cullins were created as described in the introduction section. PCR was used to generate NTD and CTD coding regions for both Cull and Cul2 respectively. These PCR reactions used pcDNACul1 and pcDNACul2 as templates. The primers used were designed to produce PCR product flanked by restriction sites for cloning into pCMV-3Tag-6 Cul3, replacing the NTD and CTD of Cul3 in this vector. Both NTD PCR products were flanked by the restriction sites Srf1 and HindIII, while both CTD PCR products were flanked by the restriction sites MfeI and ClaI.

The following primer sequences were used for the NTD and CTD PCR:

Cul1 NTD forward primer: 5'CAC TTG GCC CGG GCA ATG TCG TCA ACC CGG AGC 3'

Cul1 NTD reverse primer: 5'- GCG CAA GCT TGT TGA GTG TAG AAT TTC AGT ACA CT- 3

Cul2 NTD forward primer: 5' CAC TTG GCC CGG GCA ATG TCT TTG AAA CCA AGA3'

Cul2 NTD reverse primer: 5'- GGC CAA GCT TGC CTA TGA TAC ATA ACA AGT ACT TGT TCT TC- 3 '

Cul1 CTD forward primer: 5'- GGC CCA ATT GGA ACT AGA AGA CAC ACT CAA TCA ACT GAT- 3'

Cul1 CTD reverse primer: 5' CAC GTT ATC GAT TTA AGC CAA GTA ACT GTA GGT GTC C- 3' 
Cul2 CTD forward primer: 5'- GGC CCA ATT GGA AGT GGA AGA CAG GCT CAC GAG CTT CAT 3'

Cul2 CTD reverse primer: 5' CAC GTT ATC GAT TCA CGC GAC GTA GCT GTA 3'

Site directed mutagenesis

The restriction sites used for cloning the $\mathrm{N}$ - terminal Cul1 and Cul2 fragments into the $\mathrm{Cul} 3$ vector were already present, flanking the $\mathrm{N}$ - terminal region $\mathrm{Cul3}$. For the $\mathrm{C}$ - terminus however, we created the MfeI restriction site using site directed mutagenesis. The MfeI site was created by the addition of a single codon (TTG) at the position where we wished to create the C- terminal chimeric junction (between nucleotides 1218-1219). This insertion should result in the addition of a single leucine residue in the amino acid sequence of Cul3, between residues 406 and 407. Site directed mutagenesis was done using the QuikChange site directed mutagenesis kit (Agilent technologies).

\section{Cell culture, transfections and western blotting}

HEK (Human Embryonic Kidney) 293 cells were grown in Dulbecco's Modified Eagle Medium (DMEM) supplemented with 10\% fetal bovine serum, 1\% L- glutamine, and $1 \%$ penicillin/streptomycin.

Transfections were carried out using calcium phosphate precipitation as described previously (Clurman et al., 1996).

Western blotting was performed as follows: Approximately 48 hours after transfection, cells were harvested in versene (1mM EDTA in phosphate-buffered saline). Cells were lysed in radioprecipitation assay (RIPA) buffer supplemented with protease 
inhibitor, and phosphatase inhibitor, and 1mM DTT. Lysates were sonicated for 10 seconds. SDS PAGE was used to separate protein in the samples on $10 \%$ acrylamide gels, followed by a transfer to nitrocellulose membrane. The membranes were incubated overnight in primary antibodies. Proteins on the membrane were visualized using horseradish peroxidase conjugated secondary antibodies and enhanced chemiluminescence reagent, followed by detection of signal on a digital imager.

Antibody used: anti- FLAG M2 monoclonal antibody (Sigma Aldrich).

\section{Molecular modeling}

A molecular model of a chimeric cullin was generated using Visual Molecular Dynamics (VMD) software, downloaded from the NIH Center of Macromolecular Modeling and Bioinformatics: http://www.ks.uiuc.edu/Research/vmd

The protein data bank coordinates for the Cul1/Rbx1 crystal structure were obtained from the RSCB Protein Data Bank (PDB ID: 1 ldj).

The molecular model was generated by uploading the PDB file into the VMD program. The $\mathrm{N}$ - terminal and $\mathrm{C}$ - terminal domains that were replaced in the cullin chimeras were selected within the amino acid sequence of Cull and displayed as a different color from the rest of the model.

\section{RESULTS AND DISCUSSION}

The chimeric cullin constructs described in this chapter represent a powerful experimental tool for investigating CRL structure and function. Before experiments were conducted, all plasmids were sent to Oregon Health Sciences University for sequencing. Sequence data confirmed that all inserts were correct and in frame. 
The plasmids were then tested for protein expression in cultured cells. FLAG tagged chimeric and wild type cullin plasmids were transfected into HEK293 cells. Cells were harvested after 48 hours, lysed, and proteins were separated using SDS PAGE. Western blotting was then used to visualize proteins. As seen in Figure 2.4, all wild type and chimeric cullin constructs expressed protein in HEK293 cells. The four chimeric cullins that were generated are named for the domain of $\mathrm{Cul} 3$ that was replaced by that of Cul1 or Cul2. Thus, the four chimeras generated are denoted Cul1 NTD, Cul2 NTD, Cul1 CTD, and Cul2 CTD. For clarity, a color coded illustration for each cullin and chimera is provided in Figure 2.4.

Notably, all chimeric cullins appear to be modified with Nedd-8. Because the neddylated form of cullins has a higher molecular weight, cullins appear as a doublet on a western blot. As seen in figure 2.3, all wild type and chimeric cullin proteins appear as a doublet, with the upper and lower bands representing neddylated and unneddylated forms, respectively. The chimera containing the C- terminus of Cul2 appears to be neddylated to a lesser extent than the other chimeras, but is comparable to the amount of neddylation seen in wild type Cul2 (comparing lanes 2 and 7).

The observation that the chimeric cullins are capable of modification with Nedd-8 suggests that chimeras are likely folded into their proper conformation. When engineering chimeric proteins, it is a concern that the chimeric junction will interrupt the way in which the protein folds. Since a proper fold is critical for protein function, it is essential for chimeras to retain their native fold in order for a chimeric study to be of value. Thus, the observation that the chimeras are capable of modification with Nedd-8 
was exciting, as it provided evidence that the chimeras were properly folded, and would be useful for conducting experiments.

To illustrate where the chimeric junctions were placed within the molecular structure of Cul3, we used a modeling program to create a molecular model of a chimeric cullin protein. Protein data bank coordinates for the crystal structure of Cull were used to create this model. The model is shown in Figure 2.5. 
A

\section{Wild type Cullins}

Substrate recognition

Cullin domain/ E2 binding

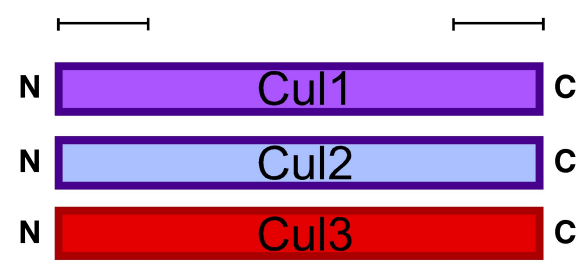

\section{$\mathrm{B} \quad \mathrm{N}$ - terminal domain chimeras}

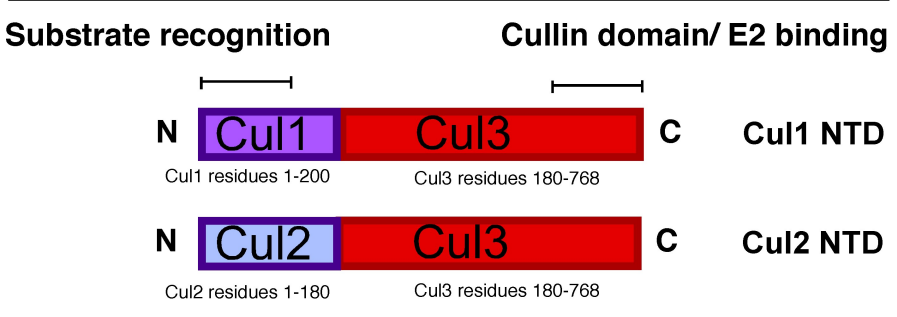

C

\section{C- terminal domain chimeras}

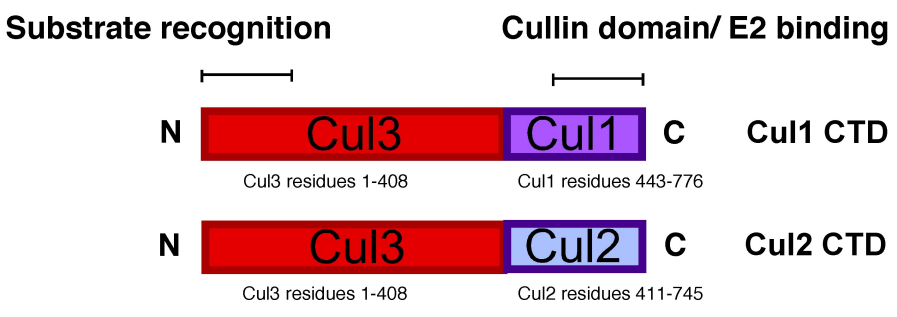

Figure 2.1: Schematic for chimeric cullin proteins

A) A schematic for the regions corresponding to the $\mathrm{N}$ - terminal domains and $\mathrm{C}$ - terminal domains of wild type Cul1, Cul2, and Cul3 proteins. B) N-terminal chimeric cullin proteins in which the NTD of Cul3 has been replaced by that of Cull or Cul2. C) C- terminal chimeric cullin proteins in which the $\mathrm{CTD}$ of $\mathrm{Cul} 3$ has been replaced by that of Cull or Cul2. 


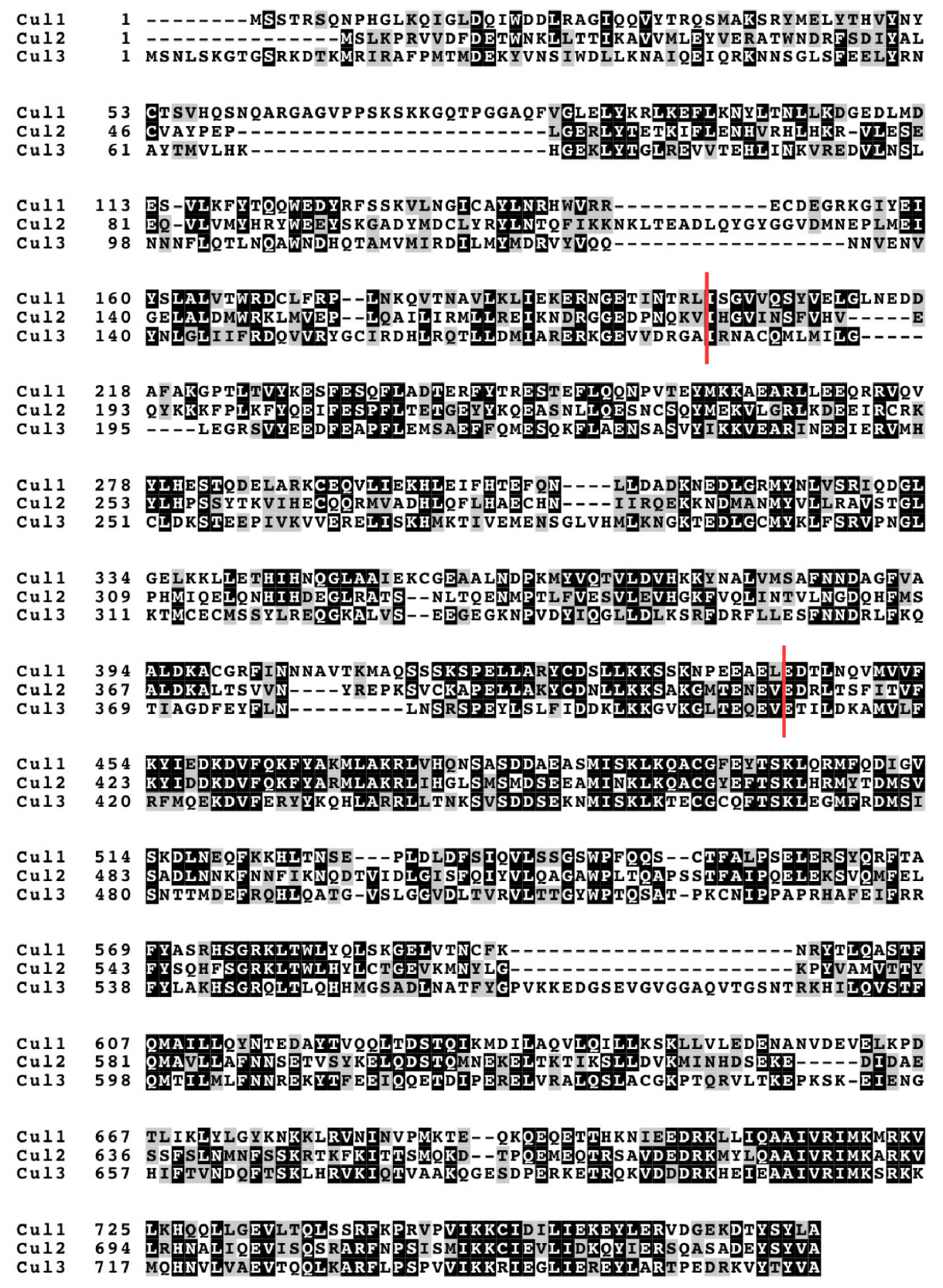

Figure 2.2: Chimeric junction placement within the amino acid sequences of $\mathrm{Cul1}$, Cul2, and Cul3

To determine where to place the chimeric junctions within the amino acid sequences of Cul1, Cul2, and $\mathrm{Cul3}$, an amino acid alignment was performed using ClustalW software. Residues that are conserved among all three cullins are boxed in black, while residues possessing similar chemistry are boxed in grey. The $\mathrm{N}$ - terminal and $\mathrm{C}$ - terminal junctions were chosen in areas of relatively high homology, and are indicated by red bars. 
A

PCR generating Cul1 $\mathrm{N}$ - terminal fragment

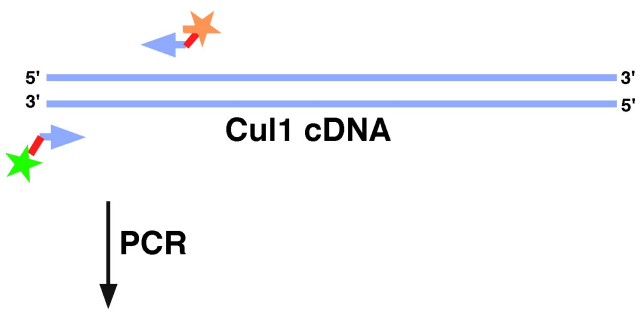

Cul1 NTD fragment flanked by restriction sites

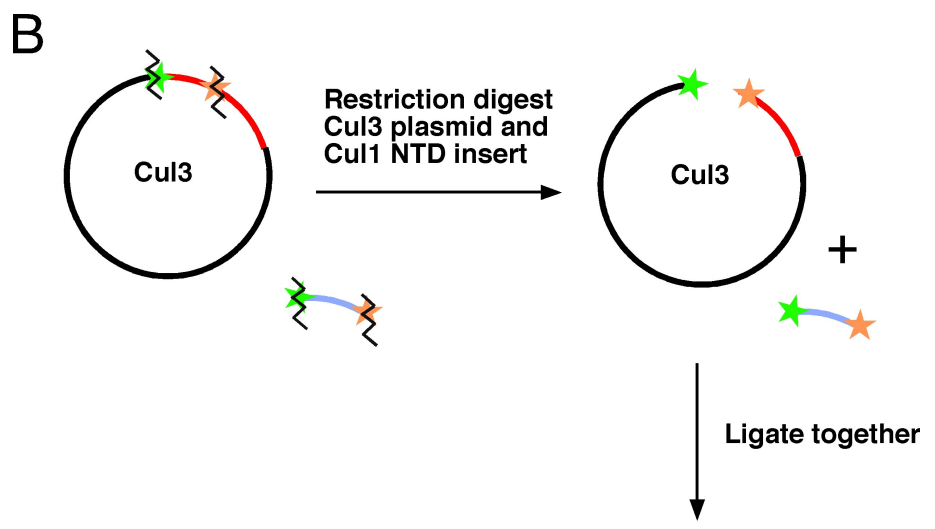

Chimeric Cul3 plasmid:
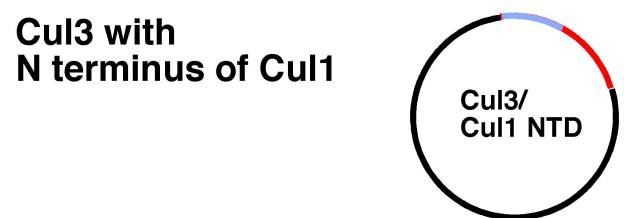

Figure 2.3: Cloning strategy for chimeric cullin constructs

The strategy for the cloning of the N- terminal chimeras is shown. A) The cDNA corresponding to the Nterminal domain (NTD) of Cul1 was amplified by PCR, flanked by the same two restriction sites flanking the NTD in the Cul3 plasmid. B) Restriction digests were carried out on the wild type Cul3 plasmid and on the Cul1 NTD PCR product. The digested DNA was combined in a ligation reaction, generating a plasmid coding for chimeric Cul3 protein: Cul3 with the NTD of Cul1. 


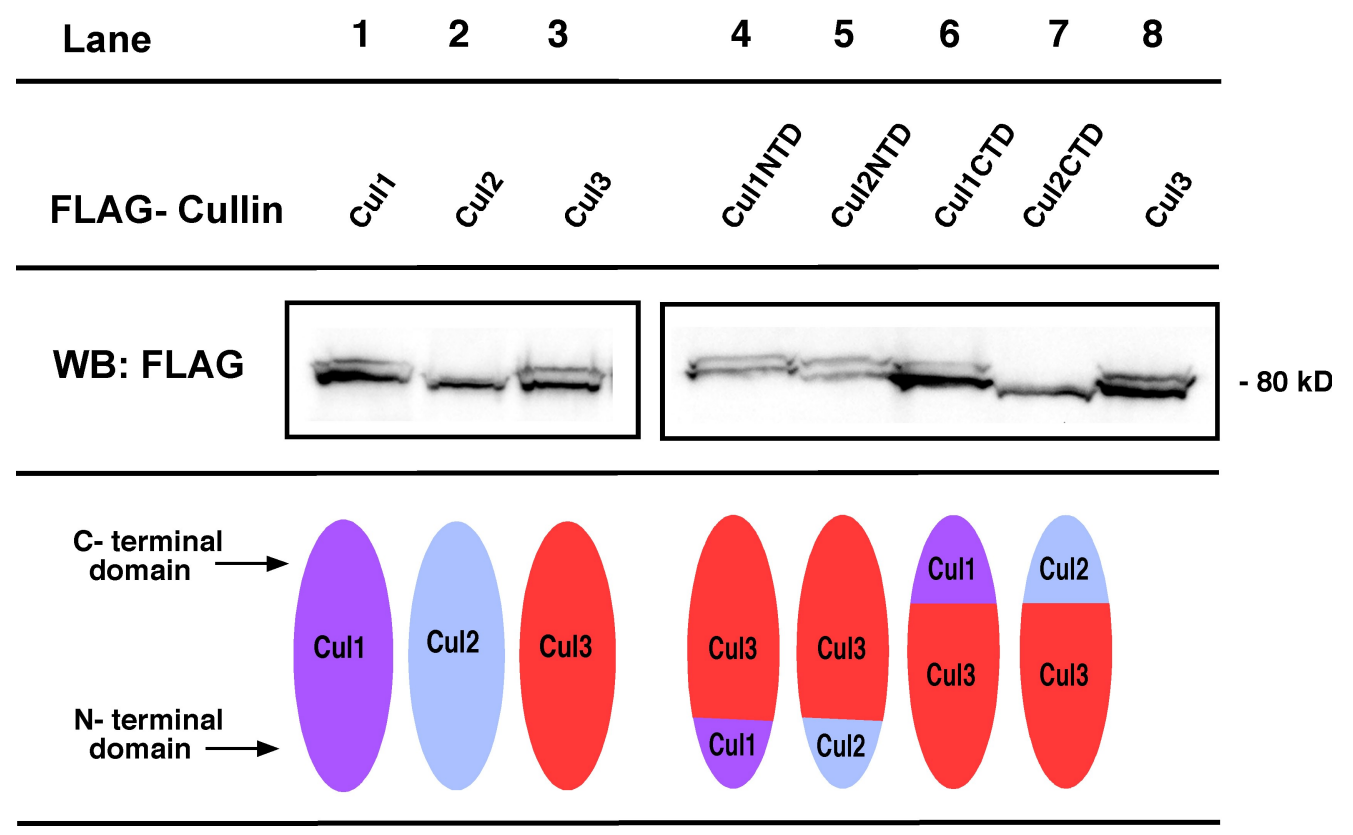

Figure 2.4: Wild type and chimeric cullin expression in HEK 293 cells

HEK 293 cells were transfected with FLAG- tagged wild type or chimeric cullins. Cells were harvested after 48 hours. Western blotting was performed using FLAG antibody to visualize protein expression. For clarity, an illustration of each cullin and chimera is provided below each lane. On the right panel, Cul3 was run on the same gel as the chimeras to illustrate that these proteins are a similar relative size. 


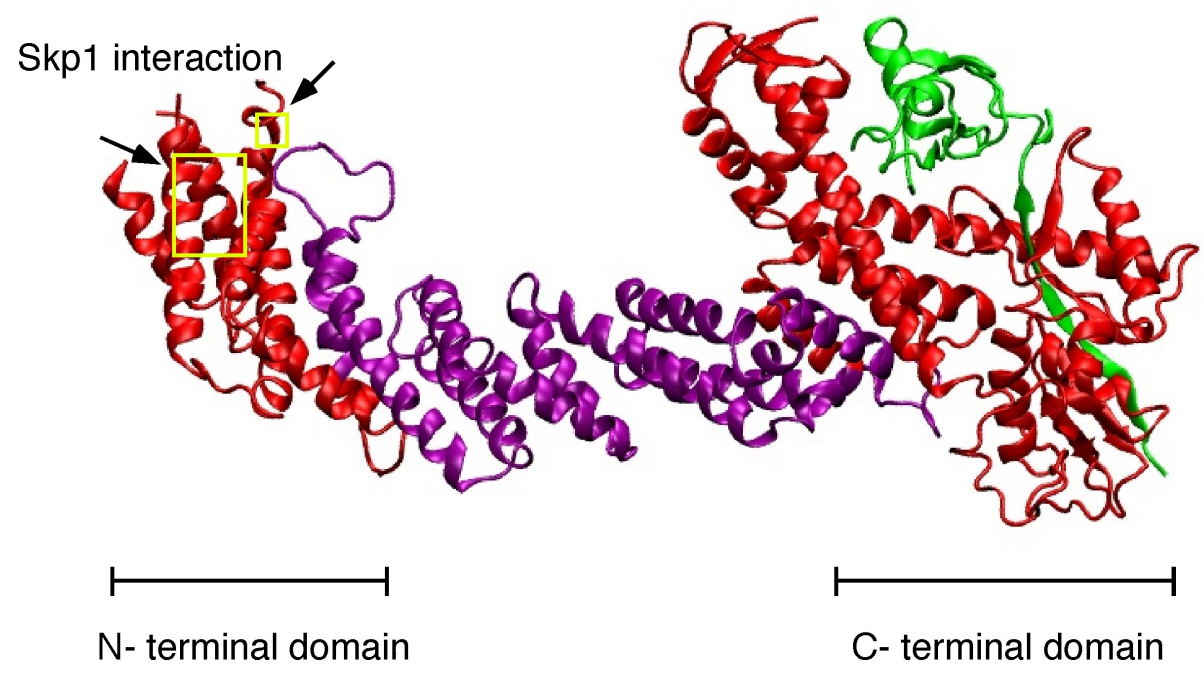

Figure 2.5: A molecular model for a cullin chimera

A molecular model for a chimeric cullin was generated using VMD molecular dynamics modeling software. The protein data bank coordinates for the crystal structure of Cull in complex with Rbx1 were used to generate this model. The $\mathrm{N}$ - terminal domain encompasses the first two hundred residues of Cull, and is shown on the left in red. The residues required for Skpl interaction within this domain are boxed in yellow. The C- terminal domain encompasses approximately three hundred residues and is shown on the right, also in red. The RING protein Rbx1 is shown in green. The chimeric junctions where the protein domains were swapped can be seen where the color changes from red to purple. While this molecular model was generated using the coordinates from the crystal structure of the Cull protein, it is likely a good approximation of where the junctions fall within the molecular structure of Cul3. 


\section{CHAPTER III}

EXAMINING SUBSTRATE ADAPTER BINDING OF WILD TYPE AND CHIMERIC CULLINS

\section{ABSTRACT}

The chimeric cullin constructs generated in this study represent a valuable tool for investigating how different functional domains of CRLs contribute to their specific functions in cells. In order to determine if the chimeras that we engineered were able to interact with their respective substrate adapters, we performed coimmunoprecipitation experiments in which we tested the ability of wild type, chimeric, or mutant cullin proteins to bind to three different substrate adapter proteins. We found that the chimera possessing the $\mathrm{C}$ - terminus of $\mathrm{Cull}$ and the $\mathrm{N}$ - terminus of $\mathrm{Cul3}$ retains the ability to interact with the BTB substrate adapters Ctb57 and KLHL3. We also found that the chimera that possesses the $\mathrm{C}$ - terminus of $\mathrm{Cul3}$ and the $\mathrm{N}$ - terminus of $\mathrm{Cull}$ was unable to interact with BTB proteins. Lastly, we found that the Cull adapter Skp1 was not able to bind to either chimera.

\section{INTRODUCTION}

The chimeric constructs generated in this study have provided us with a useful tool to investigate how the different functional domains of CRLs contribute to their unique functions in cells. By swapping out the regions responsible for Rbx1 interaction or substrate adapter recognition, we can begin to dissect how these regions contribute to CRL specific function in vivo. Therefore, we first wanted to test if the chimeric cullins we generated were capable of binding to their respective substrate adapter subunits. 
In this chapter, we examined two of the four cullin chimeras for binding to their respective substrate adapter subunits. We performed co-immunoprecipitation experiments to investigate the ability of the chimeras possessing the $\mathrm{N}$ - terminus or $\mathrm{C}$ - terminus of Cul1 to bind to BTB proteins, or Skp1 respectively. It should be noted that the chimeras possessing the $\mathrm{N}$ - terminus or $\mathrm{C}$ - terminus of $\mathrm{Cul} 2$ were not examined due to time constraints.

In recent years, interactions of substrate adapters with both Cull and Cul3 have been well characterized. Crystallographic analysis of the SCF complex revealed that the N-terminus and central stalk of Cull is comprised of three repeats each made up of five helices, which is termed the cullin repeat. At the N- terminus of Cul1, the first helical repeat binds to Skp1, which in turn binds to the F-box protein Skp2 (Zheng et al., 2002). There are over sixty F-box proteins in mammalian cells, which recognize and bind to Cul1 substrates through WD40 domains, Leucine rich repeat (LRR domains), or others (Skaar et al., 2009).

While most CRL complexes interact with substrates via two protein subunits, Cul3 interacts with substrates through a single polypeptide, which binds Cul3 through a BTB domain and interacts with substrates through various protein interaction motifs. The BTB domain was first identified as a conserved sequence found in transcriptional repressors in Drosophila (Bric-a brac, Tramtrak, and Broad complex) (Zollman et al., 1994).

Since its discovery, a growing number of proteins possessing a BTB domain have been identified as putative substrate adapters for Cul3 (Angers et al., 2006; Cullinan et 
al., 2004; Furukawa et al., 2003; Furukawa and Xiong, 2005; Geyer et al., 2003; Kobayashi et al., 2004; Kwon et al., 2006; Pintard et al., 2003; Salinas et al., 2006; Xu et al., 2003; Zhang et al., 2005). These BTB proteins bind to the N- terminus of Cul3 via the BTB domain and recognize protein substrates through protein interaction motifs such as Kelch, MATH (Mephrin and TRAF Homology), LRR (Leucine rich repeat), or zinc finger domains. Our laboratory has identified numerous BTB containing proteins that interact with Cul3 and likely serve as Cul3 substrate adapters (Cummings et al., 2009). Some of these proteins are novel and some have since been characterized by other groups. We have designated these proteins Ctb proteins (Cullin three binding).

$\mathrm{N}$ - terminal residues of $\mathrm{Cul} 3$ that are required for binding to BTB proteins have begun to be identified based on the related interface between Cul1 and Skp1. Recent investigations into the structure of the SCF complex suggest that Skp1 interacts with Cul1 at residues in helix 2 and helix 5 of the N-terminal cullin repeat (Zheng et al., 2002). Other studies revealed that deletions in analogous helices 2 and 5 at the $\mathrm{N}$ terminus of Cul3 abolishes binding to BTB proteins (Xu et al., 2003),(Pintard et al., 2003). It was later shown that four amino acids in helix five of Cul3, referred to as the LSFE sequence (amino acids 52-55), are required for BTB protein binding (Pintard et al., 2004).

In the experiments designed in this chapter, we examined the ability of wild type and chimeric cullin proteins to bind to two different BTB adapter proteins, Ctb57 and KLHL3. Ctb57 belongs to the KCTD family, a family of proteins containing a potassium channel tetramerisation domain (KCTD). Members of this group of proteins play diverse biological roles and several have recently been shown to serve as Cul3 substrate adapters. 
Ctb57, also called KCTD6, was recently characterized as a Cul3 substrate adapter that mediates the ubiquitylation of small ankyrin- 1 (sAnk1.5) a protein found in the sarcoplasmic reticulum of striated muscle cells (Lange et al.).

The other BTB protein used in this study, KLHL3, belongs to the BTB-BACKKelch family of proteins, and has been shown to serve as a Cul3 substrate adapter that mediates ubiquitylation of WNK4, a serine-threonine kinase shown to regulate sodium chloride channel function in the kidney (Shibata et al.).

Here we performed binding experiments using two $\mathrm{Cul} 3$ chimeras in which the $\mathrm{C}$ terminal and N- terminal regions were replaced by that of Cull (denoted as Cul3/Cull CTD and Cul3/Cul1 NTD, respectively). We also used a Cul3 mutant lacking the Nterminal amino acids involved in BTB protein binding (Cul3 $451-67)$. This mutant has been previously shown to be unable to bind Ctb57 or KLHL3. We performed a set of coimmunoprecipitation experiments in which we tested the ability of wild type, mutant, or Cul3/Cul1 chimeras to bind to either BTB proteins or Skp1 in cultured cells.

We found that the chimera containing the C- terminus of Cull and the Nterminus of Cul3 retains the ability to bind to BTB adapter proteins Ctb57 and KLHL3. Cul1 was unable to bind these BTB proteins, nor was the Cul3 chimera that possessed the N-terminus of Cull. These observations suggest that these chimeras have the functional binding characteristics of a Cul3/Cull chimeric protein and may function as such a chimera in vivo. 


\section{MATERIALS AND METHODS}

\section{Cell culture, plasmids and tranfections}

HEK 293 cells were grown and transfected as described in Chapter II.

Plasmid DNA: FLAG- tagged wild type and chimeric Cul1 and Cul3 were cloned into pCMV-3Tag-6 as described in Chapter II. HA-tagged Skp1 was created by cloning Skp1 into the vector CS2+HA. Myc- tagged Ctb57 and KLHL3 were previously cloned by our laboratory into the vector CS2+MT. FLAG- tagged mutant Cul3 $\Delta$ 51-67 was previously generated by our laboratory, via site- directed mutagenesis on 3XFLAG Cul3.

\section{Immunoprecipitation and Immunoblotting}

Cells were harvested and lysed as described in Chapter II. For immunoprecipitation assays, lysates were incubated with primary antibody for ten minutes, followed by incubation with sepharose beads containing immobilized protein A (RepliGen Corporation) for 2 hours at $4^{\circ} \mathrm{C}$. The samples were spun down and beads were washed twice with RIPA. SDS PAGE was used to separate protein in the samples on $10 \%$ or $15 \%$ acrylamide gels, followed by a transfer to nitrocellulose membrane. The membranes were incubated overnight in primary antibodies. Proteins on the membrane were visualized using horseradish peroxidase conjugated secondary antibodies and enhanced chemiluminescence reagent, followed by detection of signal on a digital imager.

Antibodies used for immunoprecipitation: anti- FLAG M2 monoclonal antibody (Sigma Aldrich). Antibodies used for western blotting: anti- Myc sc-789 polyclonal antibody 
(Santa Cruz Biotechnology, Santa Cruz, California), and anti- FLAG M2 monoclonal antibody (Sigma Aldrich).

RESULTS AND DISCUSSION

\section{The chimera possessing the $\mathrm{N}$ - terminus of $\mathrm{Cul} 3$ binds BTB adapter proteins}

In order to determine whether the $\mathrm{Cul} 3 / \mathrm{Cull}$ chimeras were able to bind $\mathrm{BTB}$ domain proteins Ctb57 or KLHL3, we performed co-immunoprecipitation assays using cultured HEK293 cells. Myc-tagged BTB protein Ctb57 or KHLH3 were cotransfected separately with FLAG- tagged wild type Cul1, wild type Cul3, chimeric Cul3/Cul1 CTD, chimeric Cul3/Cul1 NTD, or the BTB binding mutant Cul3 $\Delta$ 51-67. Cells were harvested after 48 hours and immunoprecipitation was carried out using FLAG antibody, followed by western blotting for Myc-Ctb57 or Myc-KLHL3 respectively.

As expected, wild type Cul3 binds Ctb57, while wild type Cull does not (Figure 3.1, lanes 2 and 3). The chimera that contains the C- terminus of Cull and the Nterminus of Cul3 retains its ability to bind Ctb57 (lane 4). Since this chimera contains the $\mathrm{N}$ - terminus of Cul3, this observation is consistent with what we know about where BTB proteins interact with Cul3. Likewise, the chimera that possesses the $\mathrm{N}$ - terminus of Cull was not able to bind Ctb57 (lane 5). This is consistent with the observation that wild type Cul1 does not bind this BTB protein. Lastly, the Cul3 mutant lacking the $\mathrm{N}$ - terminal amino acids 51-67 was not able to bind Ctb57 (lane 6). This observation is consistent with previous observations that this mutant is unable to bind Ctb57.

We next examined the binding interactions between the Cul3/Cull chimeras and the BTB protein KLHL3. We found that KLHL3 clearly binds to Cul3, but to a much 
lesser degree to Cul1 (Figure 3.2, lanes 2 and 3). The chimeric cullin that contains the Cterminus of Cull and the $\mathrm{N}$ - terminus of Cul3 also retains its ability to bind KLHL3 (lane 4). Again, this is consistent with the known interaction between BTB proteins and the Nterminus of Cul3. Interestingly, the Cul3/Cul1CTD chimera appears to bind to KLHL3 better than wild type Cul3 (comparing lanes 3 and 4). This observation is interesting because our laboratory previously noted that KLHL3 exhibits enhanced binding to Cul3 $4403-459$, a Cul3 mutant with a large deletion at the C- terminus. Since Cul3/Cul1 CTD and Cul3 $\Delta 403-459$ are both lacking a stretch of Cul3 specific sequence at the Cterminus, it is possible that disrupting some unknown structural feature at the $\mathrm{C}$ - terminus of Cul3 somehow leads to enhanced binding of this substrate adapter.

Further, while both Cul3/Cull CTD and Cul3 $\Delta 403-459$ exhibit enhanced binding to KLHL3, we have also previously observed that both of these mutants display enhanced ubiquitin laddering of Cul3 substrate cyclin E (data not shown). It is an interesting possibility that there exists a region in the $\mathrm{C}$ - terminus of $\mathrm{Cul} 3$, that when disrupted, enhances assembly with Cul3 substrate adapters as well as ubiquitylation activity. These observations will lead to interesting future experiments.

In contrast, KLHL3 does interact with the chimera that contains the $\mathrm{N}$ - terminus of Cul1 (lane 5). This is consistent with the observation that this BTB protein binds to Cul1 to a much smaller degree than Cul3. It is interesting to note that while KLHL3 shows a limited ability to bind to wild type Cull, it is not able to interact at all with this chimera which contains the N- terminus of Cull (comparing lanes 1 and 5). However, this observation is likely explained by the lower expression level of this chimera compared to wild type Cull (comparing lanes 2 and 5, lowest panel). Lastly, the Cul3 
mutant lacking the amino acids 51-67 was unable to bind KLHL3 (lane 6). This is in keeping with previous observations that this mutant does not bind to KLHL3.

\section{The adapter protein Skp1 binds to Cul1, and not to Cul3 or chimeric Cul3 proteins}

While Cul3 interacts with substrates through a single polypeptide containing a BTB domain, other cullin complexes utilize two separate protein subunits that recognize and recruit substrates. In the SCF complex, Cull binds to the adapter protein Skp1, which in turn binds F-box protein Skp2 that recognizes SCF substrates. Skp1 interacts with the $\mathrm{N}$ terminus of Cull at residues in helix 2 and 5 of the $\mathrm{N}$ terminal cullin repeat (Zheng et al., 2002). Analogous residues from helix five of Cul3 have been shown to be required for $\mathrm{Cul3}$ to bind BTB proteins.

In this experiment, we performed co- immunoprecipitation experiments to investigate the ability of wild type, chimeric, or mutant cullins to bind to Cull adapter protein Skp1 in cultured HEK293 cells. HA-tagged Skp1 was cotransfected with FLAGtagged Cul1, Cul3, Cul1CTD, Cul1NTD, or Cul3 $451-67$. The cells were harvested after 48 hours and immunoprecipitation was carried out using FLAG antibody. Western blotting was then used to probe for HA-Skp1.

Skp1 binds to Cul1 (Figure 3.3, lane 2). In contrast, Skp1 was unable to bind any of the other proteins used in this experiment (lanes 3-6) relative to background (lane 1). As expected, Skp1 did not bind Cul3 or the chimera that contains the $\mathrm{N}$ - terminus of $\mathrm{Cul} 3$ (lanes 3 and 4). However, Skp1 was also unable to bind to the Cul3 chimera that contains the N- terminus of Cul1 (lane 5). Since previous data has shown that Skp1 interacts with 
$\mathrm{N}$ - terminal residues of Cull that are contained in this chimera, this result was not anticipated. It is possible that are regions within the C- terminus of Cull that are involved in recruiting Skp1. Alternatively, it is possible that the creation of the chimeric junction interrupted a structural feature near the $\mathrm{N}$ - terminus of Cull that is involved in Skp1 binding. Further experimentation will be required to explain the observations for Skp1 interactions.

In conclusion, while the observations for Skp1 interactions are puzzling, useful information has been gained from the experiments conducted on Cul3 substrate adapters Ctb57 and KLHL3. The ability of the chimera containing the N-terminus of Cul3 to bind to these BTB proteins suggests that this chimera possesses the functional binding capabilities of a Cul1/Cul3 chimera, and may function as such in vivo. Therefore, this chimera is a good candidate for an in vivo study. 


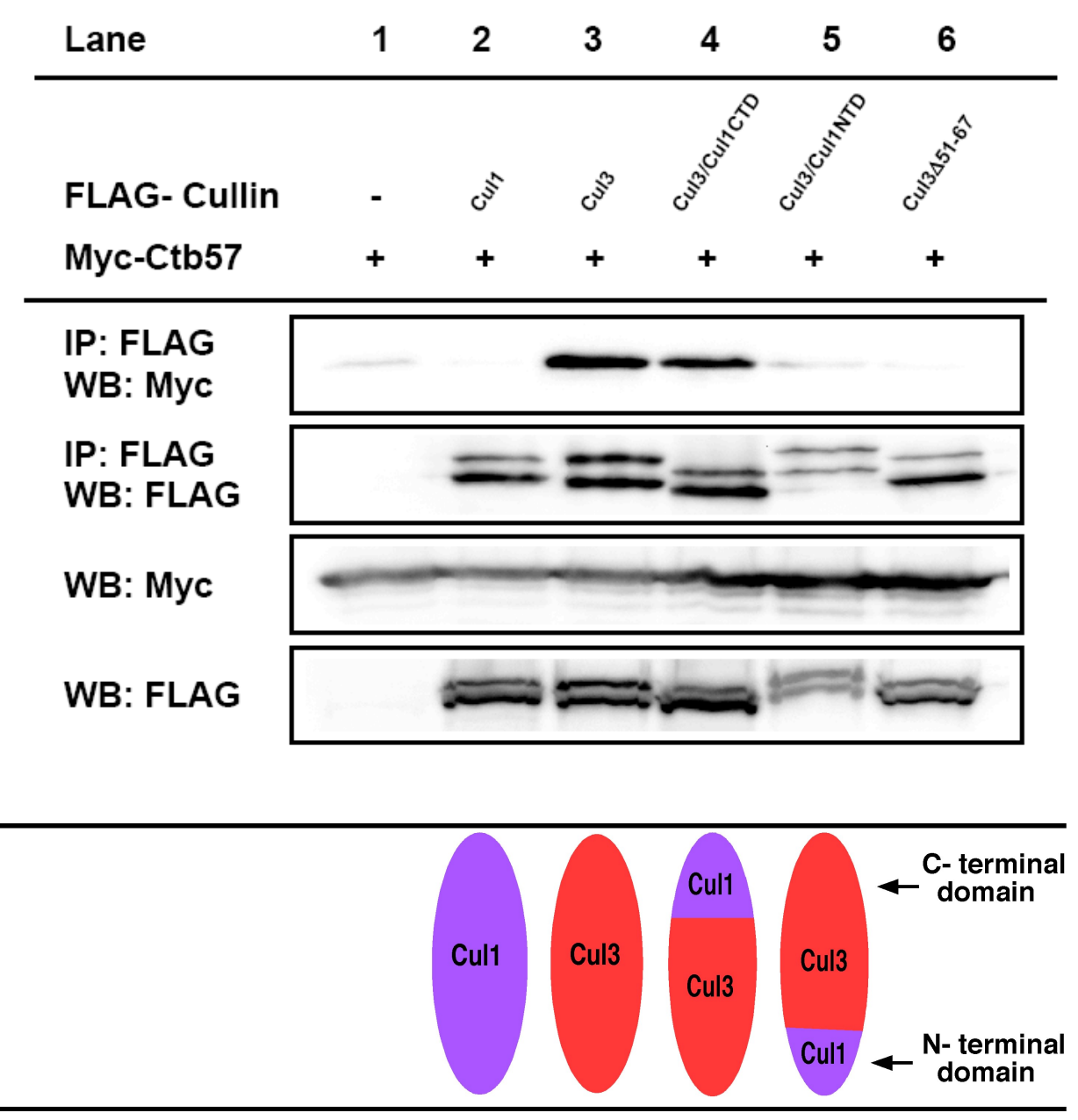

Figure 3.1: Wild type and chimeric cullin binding to BTB protein Ctb57

HEK 293 cells were cotransfected with Myc- tagged Ctb57 and FLAG- tagged wild type Cul1, Cul3, Nterminal chimeric Cul3, C-terminal chimeric Cul3, or Cul3 $\Delta 51-67$. Cells were harvested after 48 hours. Immunoprecipitation was carried out using FLAG antibody and immunoblotting was used to probe for Myc-Ctb57 binding (top panel). The second panel is a FLAG antibody control, and verifies that the immunoprecipitation pulled down FLAG- cullins. The lowest two panels indicate expression levels of Myc- Ctb57 and FLAG- cullin, respectively. 


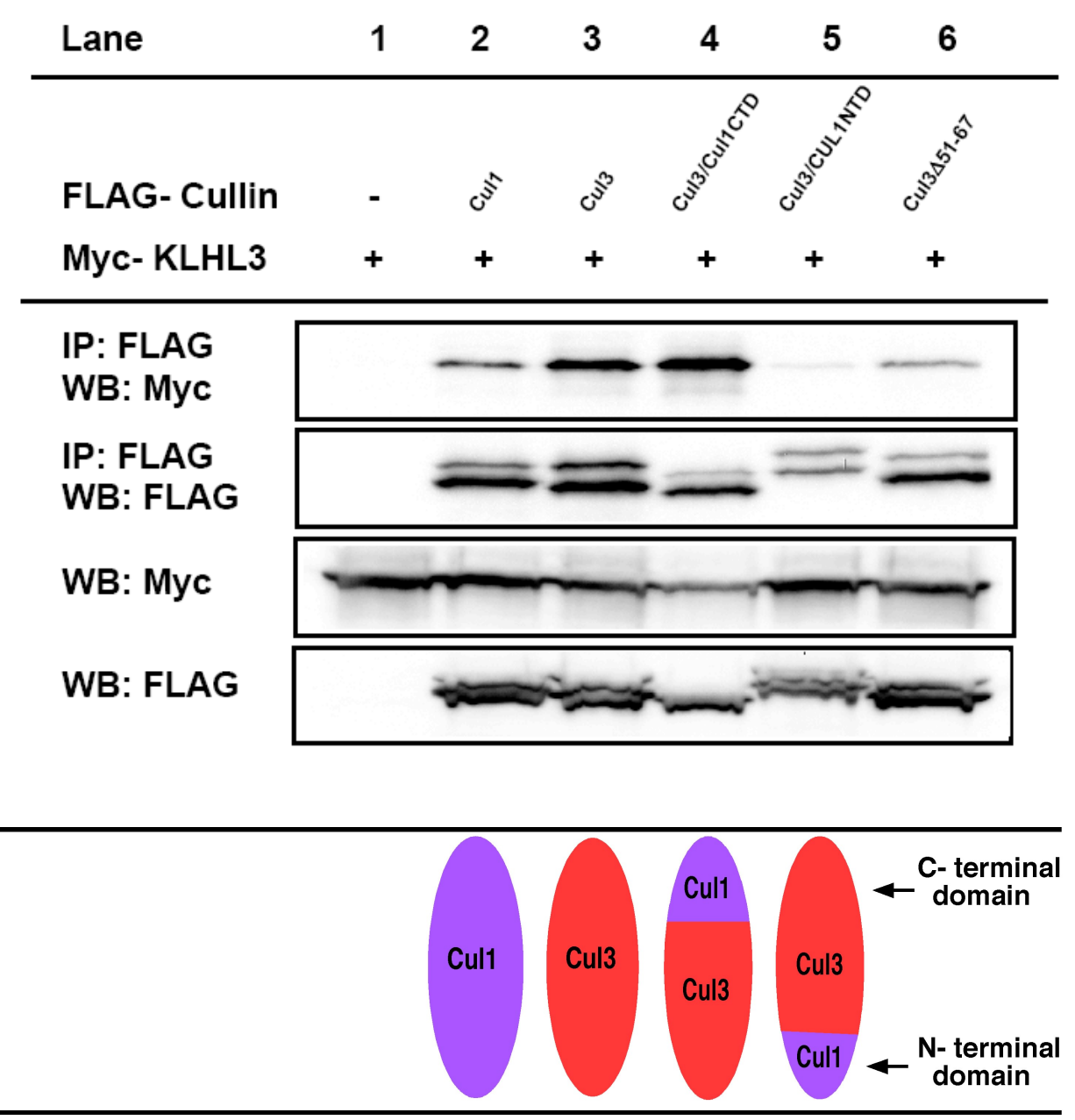

Figure 3.2: Wild type and chimeric cullin binding to BTB protein KLHL3

HEK 293 cells were cotransfected with Myc- tagged KLHL3 and FLAG- tagged wild type Cul1, Cul3, Nterminal chimeric Cul3, C-terminal chimeric Cul3, or Cul3 $\Delta 51-67$. Cells were harvested after 48 hours. Immunoprecipitation was carried out using FLAG antibody and immunoblotting was used to probe for Myc-KLHL3 binding (top panel). The second panel is a FLAG antibody control, and verifies that immunoprecipitation pulled down FLAG- cullins. The lowest two panels indicate expression levels of Myc- KLHL3 and FLAG- cullin, respectively. 


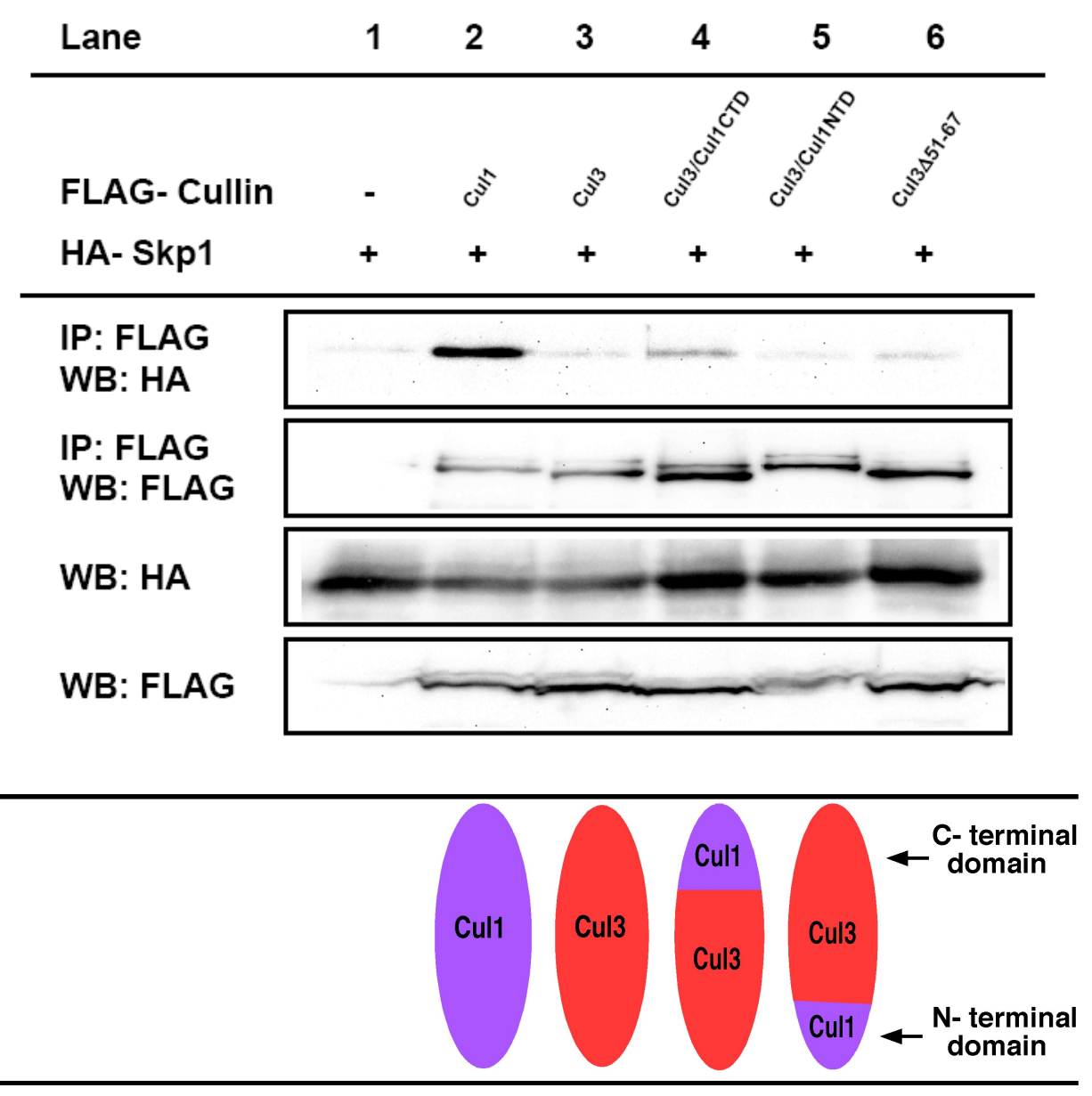

Figure 3.3: Wild type and chimeric cullin binding to adapter protein Skp1

HEK 293 cells were cotransfected with HA- tagged Skp1 and FLAG- tagged wild type Cul1, Cul3, Nterminal chimeric Cul3, C-terminal chimeric Cul3, or Cul3 $\Delta 51-67$. Cells were harvested after 48 hours. Immunoprecipitation was carried out using FLAG antibody and immunoblotting was used to probe for HASkp1 binding (top panel). The second panel is a FLAG antibody control, and verifies that the immunoprecipitation pulled down FLAG- cullins. The lowest two panels indicate expression levels of HASkp1 and FLAG- cullin, respectively. 


\section{CHAPTER IV}

\section{ANALYSIS OF E2 INTERACTIONS WITH WILD TYPE AND CHIMERIC CULLINS}

\section{ABSTRACT}

E2 enzymes have been shown to interact with the highly conserved C- terminus of cullin RING ligases (CRLs), via the RING protein Rbx1. E2 enzymes work together with CRLs to attach molecules of ubiquitin to substrates. There are approximately 38 E2 enzymes in humans, and while a growing number of studies have characterized different E2-E3 pairs, little is known about the specificity of these interactions. Here we performed co-immunoprecipitation assays to investigate the specific binding interactions between E2 enzymes and wild type, mutant or chimeric cullin proteins. We found that E2 enzyme UbE2E1 selectively binds to $\mathrm{Cul} 3$ and not to Cull. Notably, the BTB binding region at the $\mathrm{N}$ - terminus of Cul3 is required for binding to UbE2E1. Furthermore, we found that UbE2E1 also binds to Cul3 substrate adapter protein Ctb57. These experiments revealed a novel E2 interaction with the $\mathrm{N}$ - terminus of $\mathrm{Cul} 3$, as well as with a Cul3 substrate adapter protein.

\section{INTRODUCTION}

As discussed in Chapter I, CRLs are structurally similar, yet recognize unique substrates and thus carry out very different functions in cells. The current model holds that the C-terminus is highly homologous and binds E2s in a similar way, while the Nterminus is more variable and recruits unique substrates via distinct substrate adapter modules. However, open questions remain regarding this model. It has been observed that specific E2s seem to be selected by different CRLs. And, since E2s are thought to be 
responsible for the placement of branching of ubiquitin chains, the choice of E2 is essential for the type of ubiquitination that occurs. Thus, understanding how CRLs select different E2s is important for understanding how CRLs carry out unique functions in cells.

CRLs possess a highly conserved, globular C-terminal domain known as the cullin domain, that binds ring finger protein Rbx1 (also called RubI, RocI, HrtI), which serves as a docking site for ubiquitin activated E2 enzymes (Ohta et al., 1999). Based on the structure of Cul1, the globular C- terminal domain of cullins possesses conserved residues that bind to Rbx1 through an intermolecular $\beta$ sheet (Zheng et al., 2002). Rbx1 in turn interacts with E2 enzymes via its RING domain. Nedd-8 modification to a conserved lysine at the C- terminus of cullins has been shown to activate CRL complexes, presumably by causing a conformational change which frees the ring domain of Rbx1, providing a flexibility to the CRL complex that positions the E2 in closer proximity with substrate for ubiquitin transfer (Duda et al., 2008).

The human genome codes for at least 38 E2 enzymes, many of which are highly homologous in sequence and structure. E2 enzymes possess a highly conserved 150- 200 amino acid catalytic domain known as the ubiquitin conjugating (UBC) domain, which contains a catalytic cysteine residue which binds activated ubiquitin (Berleth and Pickart, 1996; Dye and Schulman, 2007; Hershko et al., 1983; Pickart, 2001). There are four major classes of E2 enzymes. Class I E2s consist of only a UBC domain, while classes II and III contain C- terminal and N- terminal extensions flanking the UBC domain. Class IV E2s possess both C- terminal and N- terminal extensions. These extensions can serve 
different functions, such as interaction with cognate $\mathrm{E} 3 \mathrm{~s}$, substrate recruitment, or dimerization (Kleiger et al., 2009; Summers et al., 2008; Xie et al.).

Recently, a growing number of studies have characterized how E2 enzymes interact with E3s. The UBC domain is made up of four $\alpha$ helices and an antiparallel $\beta$ sheet, and all E2s characterized so far interact with E3s through loop 1, loop 2, and $\alpha$ helix 1 of the UBC domain. Variations in sequence among different E2s are thought to contribute to the specificity of interactions with different E3s (Ye and Rape, 2009).

The N- terminal and C- terminal extensions of different E2s can also play diverse roles in E2/E3 interactions. Class III E2 UbcH10 (UBE2C) is known to act as an E2 for the E3 anaphase promoting complex (APC), a key player in cell cycle regulation. $\mathrm{UbcH} 10$ possesses an $\mathrm{N}$ - terminal extension that regulates ubiquitylation activity and selects which lysine residues of substrates are modified by the ubiquitin ligase complex (Summers et al., 2008). Another well- characterized E2 is cell division cycle 34 (Cdc34), a class II E2 that serves as a cognate E2 for the Cul1/ SCF complex (Goebl et al., 1988; Skowyra et al., 1997). Cdc34 possesses a C- terminal acidic tail that binds to Cul1. Phosphorylated residues on the $\mathrm{C}$ - terminal tail have been shown to regulate ubiquitylation activity (Kolman et al., 1992; Silver et al., 1992).

Despite recent advances in E2-E3 interactions, little is known about the specificity of these interactions. A single E2 can bind to several E3s, but not necessarily in the same way. Alternately, some E2s seem to interact exclusively with a single E3. Less is known about the specificity of interactions with E2s and Cullin RING ligases. To date, relatively few studies have identified E2-CRL cognate pairs. Cdc34 has been well 
characterized as a cognate E2 for the SCF complex, which has been shown to polyubiquitylate Cdk inhibitor Sic1 (Verma et al., 1997). But to date, Cdc34 has not been shown to interact with other CRLs.

To identify CRL specific interactions with E2 enzymes, we performed cotranfections and co- immunoprecipitation assays where we tested the ability of wild type and chimeric Cull and Cul3 to bind to five different E2 enzymes in cultured cells. We found that one of these E2s bind to both Cull and Cul3, while three other E2s did not bind to either cullin. Interestingly, one E2s displayed selectivity for one cullin over the other: UbE2E1 bound to Cul3 and not Cul1. Since UbE2E1 showed specificity for Cul3, we next wanted to explore what part of Cul3 was required for this E2 to bind.

Since the C- termini of cullins are highly homologous, how does a given E2 interact with one cullin and not another? What structural features of cullins are required to interact with different E2 enzymes? The chimeric cullins provided us with a direct way to address this question. Therefore, we next performed co- immunoprecipitation assays where we tested the ability of UbE2E1 to bind to wild type, chimeric, and mutant cullin proteins.

Surprisingly, we found that the C-terminus of Cul3 was not required for binding to this E2, but the N- terminus was required. Further, we found that removal of the BTB binding region of Cul3 significantly diminishes binding to UbE2E1. Additionally, coimunoprecipitation assays performed with UbE2E1 and several different BTB substrate adapter proteins revealed that UbE2E1 binds to BTB adapter protein Ctb57. Taken 
together, these data reveal a novel interaction between the E2 enzyme UbE2E1 and the $\mathrm{N}$ - terminus of Cul3.

\section{MATERIALS AND METHODS}

\section{Cell culture, plasmids and tranfections}

HEK 293 cells were grown and transfected as described in Chapter II.

Plasmid DNA: FLAG- tagged wild type Cul1 and Cul3, and chimeric Cul3/Cul1 were cloned into pCMV-3Tag-6 as described in Chapter II. Cul3 was also cloned into the vector 3XFLAG. FLAG tagged Cul3 mutants $\Delta 51-67$ and $\Delta 403-457$ were previously made by our laboratory using the QuikChange site- directed mutagenesis kit (Agilent Technologies). Both Cul3 mutations were made on Cul3 that was cloned into the vector 3XFLAG. Myc-tagged E2s (UbE2E1, UbcH5b, UbcH7, and UbcH10) in the vector pKMyc were donated from the Plafker laboratory (Oklahoma Medical Research Foundation, Oklahoma City). UbcM2 was cloned into the vector CS2+MT.

\section{Immunoprecipitation and Immunoblotting}

Immunoprecipitation and western blotting was performed as described in Chapter III. Antibodies used for immunoprecipitation: anti- FLAG M2 monoclonal antibody (Sigma Aldrich), or anti- Myc sc-789 polyclonal antibody (Santa Cruz Biotechnology, Santa Cruz, California).

Antibodies used for western blotting: anti- Myc sc-789 polyclonal antibody (Santa Cruz Biotechnology, Santa Cruz, California), and anti- FLAG M2 monoclonal antibody (Sigma Aldrich) 


\section{RESULTS AND DISCUSSION}

\section{Cul1 and Cul3 exhibit differential binding to E2 enzymes}

Since little is known about the specificity of interactions between E2s and different cullins, we first wanted to determine if there were E2 enzymes that showed selectivity for binding to either Cull or Cul3. To investigate this, we cotransfected FLAG- tagged wild type Cul1 or Cul3 separately with five different Myc- tagged E2s. Immunoprecipitation was then performed using FLAG antibody, followed by western blotting to probe for E2 binding.

There were three E2s ( $\mathrm{UbcH} 5 \mathrm{~b}, \mathrm{UbcH} 7$, and $\mathrm{UbcH} 10)$ that did not appear to bind to either Cul1 or Cul3 (Figure 4.1). To date, none of these E2s have been published to interact with cullin ligases, but all been characterized for their interactions with other types of E3 ligases. For example, UbcH5b has been shown to facilitate the ubiquitiylation of p53 by the E3 ligase Mdm2 (Saville et al., 2004).

One of the E2s tested, UbcM2, was able to bind to both Cul1 and Cul3 (Figure 4.2). UbcM2 has been previously characterized as interacting with Cull and Cul3 in an in vitro study (Plafker et al., 2009), yet its interaction with cullin complexes in vivo had not yet been tested.

Interestingly, one of the E2s tested appeared to be selective for Cul3. UbE2E1 was shown to bind to $\mathrm{Cul3}$, but not to Cull (Figure 4.3). This E2 was previously characterized for its role in histone ubiquitination (Plafker et al.; Sarkari et al.), but had not been characterized for interaction with any of the cullin ligases. 
The selectivity observed in this experiment raises several interesting questions. Since the C- terminus of Cull and Cul3 are highly homologous, and both interact with Rbx1 in a similar way, how does a single E2 interact with one cullin and not the other? What features of these two cullins are responsible for differential binding to a single E2? To begin to address these questions, we next performed a set of binding experiments with UbE2E1 and Cul3/Cul1 chimeric cullins.

\section{The BTB region of $\mathrm{Cul} 3$ is required for binding to E2 enzyme UbE2E1}

Since we had observed that UbE2E1 binds to Cul3 and was unable to interact with Cul1, we wanted to determine which part of Cul3 was required for UbE2E1 binding. To investigate this, we performed cotransfections and co-immunoprecipitation experiments to examine binding interactions between this $\mathrm{E} 2$ and chimeric $\mathrm{Cul} / \mathrm{Cul}$ proteins or mutant cullin proteins.

HEK293 cells were cotransfected with Myc-tagged UbE2E1 and FLAG-tagged wild type Cul1, wild type Cul3, chimeric Cul3 possessing the C- terminus of Cul1 (Cul1CTD), Cul3 possessing the N- terminus of Cul1 (Cul1NTD), a mutant Cul3 lacking the N- terminal residues involved in BTB domain binding (Cul3 $\Delta 51-67)$, or a mutant Cul3 lacking a large region of the $\mathrm{C}$ terminus (Cul3 $\Delta 403-459)$. Immunoprecipitation with FLAG antibody was then performed, followed by western blotting to probe for MycUbE2E1 binding.

The current model of CRL assembly suggests that E2 enzymes interact with cullin based E3s via interaction with the ring domain protein $\mathrm{Rbx} 1$ at the $\mathrm{C}$ - terminus of cullins. Since UbE2E1 was able to bind to Cul3 and not to Cul1, we expected that the Cul3 
chimera that contained the C- terminus of Cull would not be able to bind this E2. We were surprised to see that this did not occur (Figure 4.4, lane 4). In fact, the C- terminal chimera appeared to have an enhanced ability to bind this E2. Also, the mutant Cul3 that contains a large deletion at the $\mathrm{C}$ terminus (Cul3 $\Delta 403-459)$ was also able to interact with UbE2E1 (lane 7). These observations suggest that the $\mathrm{C}$ - terminus of $\mathrm{Cul} 3$ is not required for binding to this E2.

Further, we expected that replacing the $\mathrm{N}$ - terminus of $\mathrm{Cul3}$ with that of $\mathrm{Cul1}$ would have little effect on the binding of this E2, as the current model suggests that the $\mathrm{N}$ - terminus is not involved. Surprisingly, replacing the N- terminus of Cul3 with that of Cul1 eliminated binding (lane 5). Moreover, the Cul3 mutant lacking the residues involved in BTB protein binding (Cul3 $\Delta 51-67)$ also significantly diminished binding (lane 6). Taken together, these data suggest that the $\mathrm{N}$ - terminus, specifically the BTB binding region, is required for UbE2E1 interaction with Cul3.

These observations do not align with the current model of how cullin E3 ligases interact with E2s. However, as more E2- E3 interactions are characterized, it becomes clear that E2s can in fact interact with E3s in variable ways. However, to date, the only example of an E2 interaction with the $\mathrm{N}$ - terminus of CRL complexes was seen between the metazoan E2 UbcM2 and Cul3.

As previously mentioned, an in vitro transcription/ translation study revealed that UbcM2 interacts with the $\mathrm{N}$ - terminus of $\mathrm{Cul3}$, and requires the BTB binding region as well as the presence of a substrate adapter to bind to the cullin complex (Plafker et al., 2009). The same study also showed that UbE2E1 and UbE2E2 bind the $\mathrm{N}$ terminus of 
Cul3 in vitro, suggesting that interaction with the $\mathrm{N}$ - terminus of cullin complexes may be a trait shared by all class III E2s.

It is an interesting possibility that BTB substrate adapters, or the $\mathrm{N}$ - terminus of Cul3 itself is somehow involved in recruiting certain E2s to the Cul3 complex. Alternatively, another possibility is that UbE2E1 is not serving as an ubiquitin conjugating enzyme with Cul3 but is instead bound to $\mathrm{Cul3}$ as a substrate. Since substrates are recruited to the Cul3 complex by BTB proteins at the $\mathrm{N}$ terminus, this could explain the observation that the BTB binding domain of $\mathrm{Cul} 3$ is required for this UbE2E1 to bind. To investigate these observations further, we next tested the ability of this E2 to interact with BTB domain containing proteins.

\section{UbE2E1 binds to the Cul3 adapter protein Ctb57}

Since we had shown that the $\mathrm{N}$ - terminus of Cul3 is required for interaction with UbE2E1, we wanted to determine whether it is interacting directly with the $\mathrm{N}$ - terminus of $\mathrm{Cul3}$, or to a substrate adapter protein of the Cul3 complex. To begin to investigate this, HEK293 cells were cotransfected with HA-tagged UbE2E1 and five different Myctagged BTB proteins previously shown to interact with Cul3 (Ctb3, Ctb57, Ctb73, Ctb75, and KLHL3). Immunoprecipitation was then performed with HA antibody followed by western blotting to probe for BTB protein interaction. It should be noted that one of the BTB proteins in this experiment did not express (Ctb3, lane 2 middle panel), and so no conclusion can be drawn about the interaction between $\mathrm{Ctb} 3$ and UbE2E1 from this experiment. However, of the five BTB domain proteins tested, one protein (Ctb57) displayed a strong interaction with UbE2E1 (Figure 4.5, lane 3). 
As discussed in Chapter III, Ctb57 is a member of the KCTD (potassium channel tetramerization domain) family of BTB proteins, and has been characterized as a Cul3 substrate adapter that targets small ankyrin- 1, a protein found in striated muscle cells (Lange et al.). To date, this BTB protein has not been observed to interact with E2 enzymes. Thus, this experiment revealed a novel interaction between UbE2E1 and Ctb57.

Taken together, the observations that $\mathrm{UbE} 2 \mathrm{E} 1$ requires the $\mathrm{BTB}$ binding region to bind $\mathrm{Cul3}$ and also interacts with the Cul3 substrate adapter Ctb57 can be explained in more than one way. One possibility is that UbE2E1 is recruited to the Cul3 complex by certain BTB substrate adapters such as Ctb57. Though to date such an interaction has not yet been observed, it is possible that certain BTB proteins bind both an E2 and substrates, bringing them in close proximity to each other for ubiquitin transfer.

One way to further investigate this idea would be to determine which part of Ctb57 binds UbE2E1. As discussed previously, the BTB domain of Ctb57 interacts with the N- terminus of Cul3 while a separate domain acts to recognize substrates. Therefore, to determine which part of Ctb57 binds UbE2E1, the next step would be to perform binding assays on mutant versions of Ctb57 in which the BTB domain or substrate interaction domains have been disrupted. Unfortunately, at the time of this writing our laboratory does not yet possess mutants for Ctb57. Therefore those experiments will be delayed until Ctb57 mutagenesis can be performed and confirmed.

The possibility remains that $\mathrm{UbE} 2 \mathrm{E} 1$ is not serving as an ubiquitin conjugating enzyme with the Cul3 complex, but is instead bound by Cul3/Ctb57 as a substrate. To investigate this further, two approaches could be taken. First, since all E2s described so 
far have been shown to interact with Ring E3 ligases via RING domain proteins, we could test the ability of this E2 to bind to a Cul3 mutant that is unable to bind Rbx1. Thus, it could be determined if UbE2E1 requires Rbx1 to bind Cul3. Another approach would be to perform ubiquitination assays, to determine if UbE2E1 is ubiquitinated in the presence of Cul3. This information would further clarify the interaction between Cul3 and UbE2E1.

The experiments described in this chapter provided interesting new information regarding CRL interactions with E2 enzymes. The work described here identified two E2 enzymes (UbCM2 and UbE2E1) that interact with CRLs and had not been previously characterized in vivo. Further, this work identified a novel interaction between Cul3 and UbE2E1. While more experimentation is required to further clarify this interaction, it represents interesting preliminary data for further investigation. 
A

\begin{tabular}{lccc} 
Lane & $\mathbf{1}$ & $\mathbf{2}$ & $\mathbf{3}$ \\
\hline FLAG- Cullin & - & Cul1 & Cul3 \\
Myc- UbcH5b & + & + & + \\
\hline IP: FLAG & $\begin{array}{l}\text { Myc signal not detected } \\
\text { No binding observed }\end{array}$ \\
WB: Myc & & \\
IP: FLAG & \\
WB: FLAG & \\
WB: Myc & \\
WB: FLAG &
\end{tabular}

C

\begin{tabular}{lccc} 
Lane & $\mathbf{1}$ & $\mathbf{2}$ & $\mathbf{3}$ \\
\hline FLAG- Cullin & - & Cul1 & Cul3 \\
Myc- UbcH10 & + & + & + \\
\hline IP: FLAG & $\begin{array}{l}\text { Myc signal not detected } \\
\text { No binding observed }\end{array}$ \\
WB: Myc & \\
IP: FLAG \\
WB: FLAG \\
WB: Myc
\end{tabular}

B

\begin{tabular}{lccc} 
Lane & $\mathbf{1}$ & $\mathbf{2}$ & $\mathbf{3}$ \\
\hline FLAG- Cullin & - & Cul1 & Cul3 \\
Myc- UbcH7 & + & + & + \\
\hline IP: FLAG & $\begin{array}{l}\text { Myc signal not detected } \\
\text { No binding observed }\end{array}$ \\
WB: Myc & & \\
IP: FLAG & \\
WB: FLAG & \\
WB: Myc & \\
WB: FLAG &
\end{tabular}

Figure 4.1: E2 enzymes UbcH5b, UbcH7, and UbcH10 do not bind either Cul1 or Cul3

HEK 293 cells were cotransfected with Myc- tagged E2 enzymes and FLAG- tagged Cul1 or Cul3. Cells were harvested after 48 hours. Immunoprecipitation was carried out using FLAG antibody and immunoblotting was used to probe for Myc-E2 binding. (A, B, C) Myc- signal was not detected, indicating that these E2s do not bind Cul1 or Cul3 (top panels). The second panel is a FLAG antibody control, and verifies that the immunoprecipitation pulled down FLAG- cullins. The lowest two panels indicate expression levels of Myc- E2 and FLAG- cullin, respectively. 


\begin{tabular}{|c|c|c|c|}
\hline Lane & 1 & 2 & 3 \\
\hline FLAG- Cullin & . & Cul1 & Cul3 \\
\hline Myc- UbcM2 & + & + & + \\
\hline $\begin{array}{l}\text { IP: FLAG } \\
\text { WB: Myc }\end{array}$ & & - & - \\
\hline WB: Myc & & & $=$ \\
\hline WB: FLAG & & rat & $m$ \\
\hline
\end{tabular}

Figure 4.2: E2 enzyme UbcM2 binds both Cul1 and Cul3

HEK 293 cells were cotransfected with Myc- tagged UbcM2 and FLAG- tagged Cul1 or Cul3. Cells were harvested after 48 hours. Immunoprecipitation was carried out using FLAG antibody and immunoblotting was used to probe for Myc-UbcM2 binding (top panel). The lowest two panels indicate expression levels of Myc- UbcM2 and FLAG- cullin, respectively.

\begin{tabular}{llcc} 
Lane & 1 & 2 & 3 \\
\hline FLAG- Cullin & - & Cul1 & Cul3 \\
Myc- UbE2E1 & + & + & + \\
\hline IP: FLAG & & & \\
WB: Myc & & & \\
IP: FLAG & & \\
WB: FLAG & & \\
WB: Myc & & \\
WB: FLAG & & \\
\hline
\end{tabular}

\section{Figure 4.3: E2 enzyme UbE2E1 binds Cul3 and not Cul1}

HEK 293 cells were cotransfected with Myc- tagged UbE2E1 and FLAG- tagged Cul1 or Cul3. Cells were harvested after 48 hours. Immunoprecipitation was carried out using FLAG antibody and immunoblotting was used to probe for Myc- UbE2E1 binding (top panel). The second panel is a FLAG antibody control, and verifies that the immunoprecipitation pulled down FLAG- cullins. The lowest two panels indicate expression levels of Myc- UbE2E1 and FLAG- cullin, respectively. 


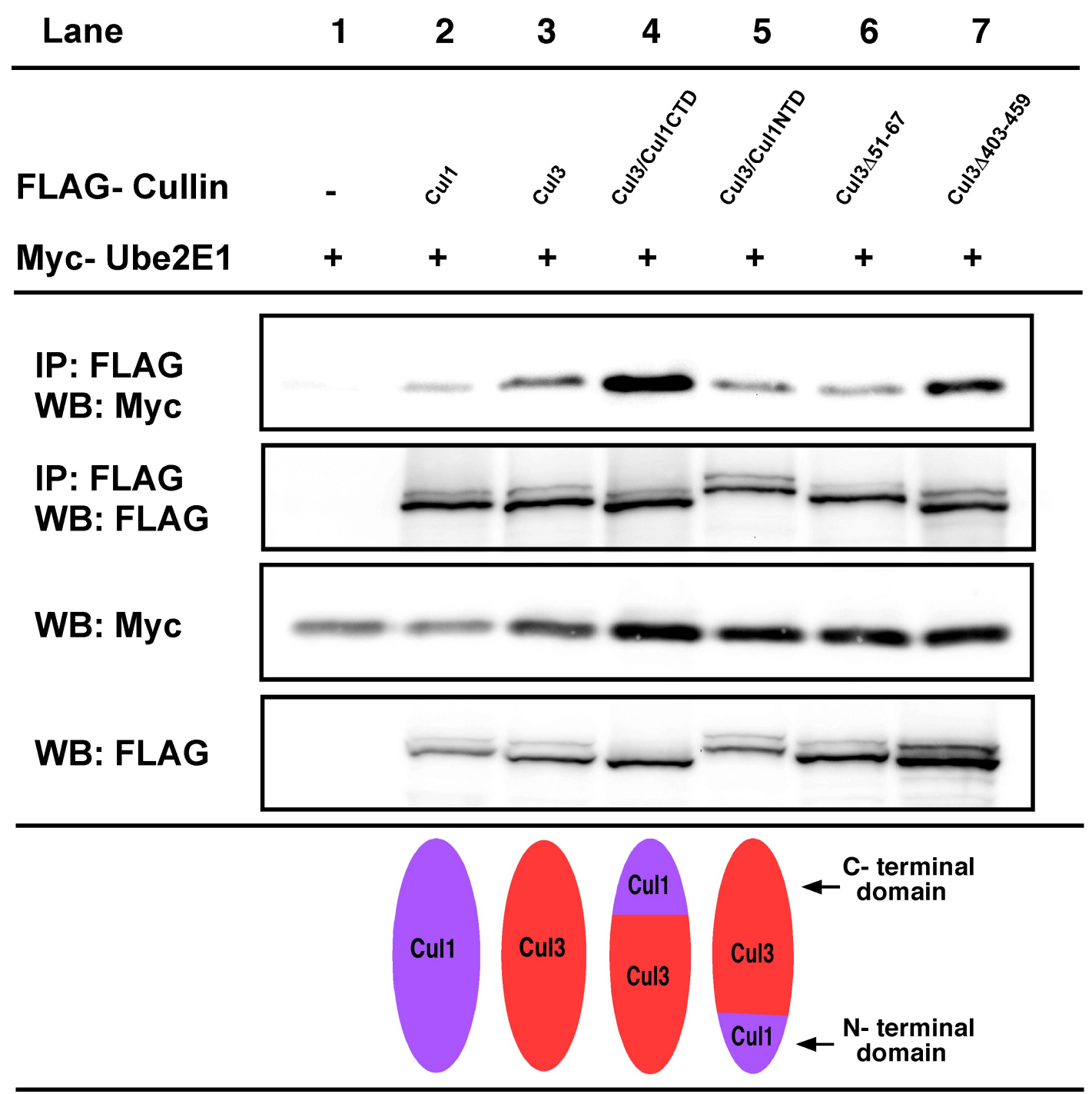

Figure 4.4: Wild type and chimeric cullin binding to E2 enzyme Ube2E1

HEK 293 cells were cotransfected with Myc- tagged Ube2E11 and FLAG- tagged wild type Cul1, Cul3, N

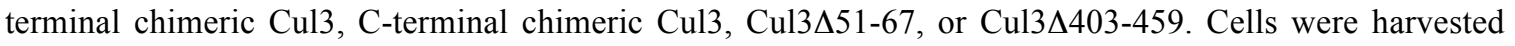
after 48 hours. Immunoprecipitation was carried out using FLAG antibody and immunoblotting was used to probe for Myc-Ube2E1 binding (top panel). The second panel is a FLAG antibody control, and verifies that the immunoprecipitation pulled down FLAG- cullins. The lowest two panels indicate expression levels of Myc- UbE2E1 and FLAG- cullin, respectively. For clarity, an illustration of wild type and chimeric cullins is provided below lanes $2-5$. 


\begin{tabular}{|c|c|c|c|c|c|c|}
\hline Lane & 1 & 2 & 3 & 4 & 5 & 6 \\
\hline Мyс- ВТВ & - & ctb3 & Ctb57 & Ctb73 & Ctb75 & KLHLз \\
\hline HA-Ube2E1 & + & + & + & + & + & + \\
\hline $\begin{array}{l}\text { IP: Myc } \\
\text { WB: HA }\end{array}$ & 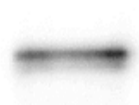 & & & & $=$ & $=$ \\
\hline WB: Myc & & & & & - & \\
\hline WB: HA & & & & & & \\
\hline
\end{tabular}

Figure 4.5: E2 enzyme Ube2E1 binding to BTB proteins

HEK 293 cells were cotransfected with HA- tagged Ube2E1 and 5 different Myc- tagged BTB domain proteins (Ctb3, Ctb57, Ctb73, Ctb75, and KLHL3. Cells were harvested after 48 hours. Immunoprecipitation was carried out using Myc antibody and immunoblotting was used to probe for HAUbe2E1 binding (top panel). The lowest two panels indicate expression levels of Myc- BTB proteins and HA-UbE2E1 respectively. 


\section{CHAPTER V}

\section{SIGNIFICANCE AND FUTURE DIRECTIONS FOR THIS STUDY}

The chimeric cullins generated in this study have contributed valuable information to the current body of knowledge regarding CRL complexes in cells. In Chapter IV, the chimeric cullins allowed us to identify an E2 enzyme, UbE2E1, which appears to engage in a novel interaction with the $\mathrm{N}$ - terminus of $\mathrm{Cul3}$ and with the BTB protein $\mathrm{Ctb} 57$. Thus, by replacing replace large regions of the $\mathrm{Cul3}$ protein with regions from closely related homologues, we have begun to map which regions of Cul3 are involved in Cul3 interactions with other proteins.

The results described in this thesis have also generated interesting new questions to address in future experiments. For example, in Chapter III we observed that the chimera possessing the $\mathrm{C}$ - terminus of Cul1 displayed an enhanced ability to bind the Cul3 substrate adapter KLHL3. As discussed previously, this observation was intriguing because we have also observed enhanced binding of KLHL3 by the mutant Cul3 $\Delta 403$ 459. Moreover, both the Cul1CTD chimera and Cul3 $\Delta$ 403-459 have displayed an enhanced ability to ubiquitinate cyclin E.

Since both of these mutants lack a stretch of Cul3 residues near the C-terminus, it is an intriguing possibility that disrupting this region somehow activates the Cul3 complex. In fact, a similar observation was seen recently by another group, in a study conducted on the SCF complex. In that study, deletion of extreme C-terminal residues of Cull dramatically increased the ability of the SCF complex to bind and ubiquitinate a 
Cul1 substrate. The authors suggested that the interface with Rbx1 and the extreme Cterminal residues of Cull play an autoinhibitory role, and that when disrupted, activates the Cull complex (Yamoah et al., 2008). It is possible that a similar regulatory mechanism exists within the Cul3 residues 403-459 near the C- terminus of Cul3. These ideas will require further investigation, but could uncover an undescribed regulatory mechanism for $\mathrm{Cul} 3$ activity.

The experiments in Chapter IV also generated interesting questions for further investigation. In these experiments, we observed that the E2 enzyme UbE2E1 displays a novel interaction with the $\mathrm{N}$ - terminus of $\mathrm{Cul} 3$ and the BTB adapter protein Ctb57. This was an interesting observation, as no E2s characterized so far have been shown to interact with the N-terminus of cullins in vivo. It is possible that this interaction represents a new role for Cul3 substrate adapters in recruiting E2s for ubiquitin transfer. Alternately, it is possible that this E2 is not acting as an ubiquitin conjugating E2, but is instead bound to Cul3 as a substrate. These possibilities are illustrated in Figure 5.1.

To further investigate the interaction between UbE2E1 and Cul3, several approaches could be taken. First, we could investigate if this E2 also requires Rbx1 to bind the Cul3 complex. Our laboratory possesses a Cul3 point mutant (Cul3 F665D) that is unable to bind Rbx1. Therefore, a co- immunoprecipitation experiment will be carried out to see if UbE2E1 binds this Cul3 mutant. If UbE2E1 does not bind Cul3 F665D, then that would suggest that UbE2E1 requires Rbx1 to bind Cul3. That would be an interesting result, because it would suggest that this E2 is binding both Rbx1 at the C- 
terminus of Cul3, as well as interacting with a substrate adapter at the $\mathrm{N}$ - terminus of Cul3.

If UbE2E1 does bind Cul3F665D, this would also be an interesting result, because it would suggest a previously undescribed interaction of an $\mathrm{E} 2$ with only the $\mathrm{N}$ - terminus of a CRL complex. This observation would provide additional evidence for the possibility that UbE2E1 is a substrate of the Cul3 complex. While E2s have been shown to be regulated by auto-ubiquitination, little is known about the ubiquitination of E2s by other E2/E3 pairs. Therefore, to investigate if UbE2E1 is a substrate of Cul3, we could test to see if UbE2E1 is ubiquitinated by Cul3 in vivo. These experiments will further clarify the interaction observed between these important proteins.

The ultimate aim for the work described in this thesis is to map the functional regions of Cul3 that are responsible for its unique activity in cells. Therefore, an important goal for this project is to perform complementation assays to determine if chimeric cullin proteins are capable of performing Cul3 functions in vivo. This information will contribute to our understanding of what parts of the Cul3 contribute to Cul3 specific functions.

As mentioned in Chapter I, our laboratory possesses a conditional knock out of Cul3. We possess mouse embryonic fibroblasts (MEFs) that contain two copies of the Cul3 allele flanked by LoxP sites, as well as an inducible Cre recombinase transgene. The addition of the drug tamoxifen to these cell lines induces recombination by Cre, resulting in the removal of the Cul3 allele. This system allows us to tightly control the expression of endogenous Cul3. Therefore, complementation assays can be performed in 
which we can test the ability of the chimeric cullins to rescue, or complement, the phenotypes associated with the loss of Cul3.

Because $\mathrm{Cul} 3$ is essential for a wide range of processes, the loss of $\mathrm{Cul} 3$ will have observable phenotypes in these cell lines. Just as the loss of Cul3 in mice results in early embryonic arrest, deletion of Cul3 in MEF cell lines drastically reduces cell viability. Therefore, one complementation assay that will be performed with the cullin chimeras will be to determine if expression of a chimera can restore viability to cells in which endogenous Cul3 has been deleted. If a given chimera can restore viability, then that would suggest that the chimera is capable of performing Cul3 essential functions.

Since the loss of Cul3 will likely have other observable phenotypes beyond cell viability, other complementation assays can also be performed with the cullin chimeras. For example, we could look at the ability of a chimera to ubiquitinate Cul3 specific substrates. Alternately, we could use flow cytometry to establish cell cycle profiles for cell lines with and without $\mathrm{Cul3}$, and then examine if a chimera is able to complement the cell cycle profile associated with the loss of Cul3. These experiments will provide valuable information regarding the regions of $\mathrm{Cul} 3$ that are required for its many important activities in cells. In this way, the chimeras generated in this study will continue to be a valued tool for investigations in our laboratory. 

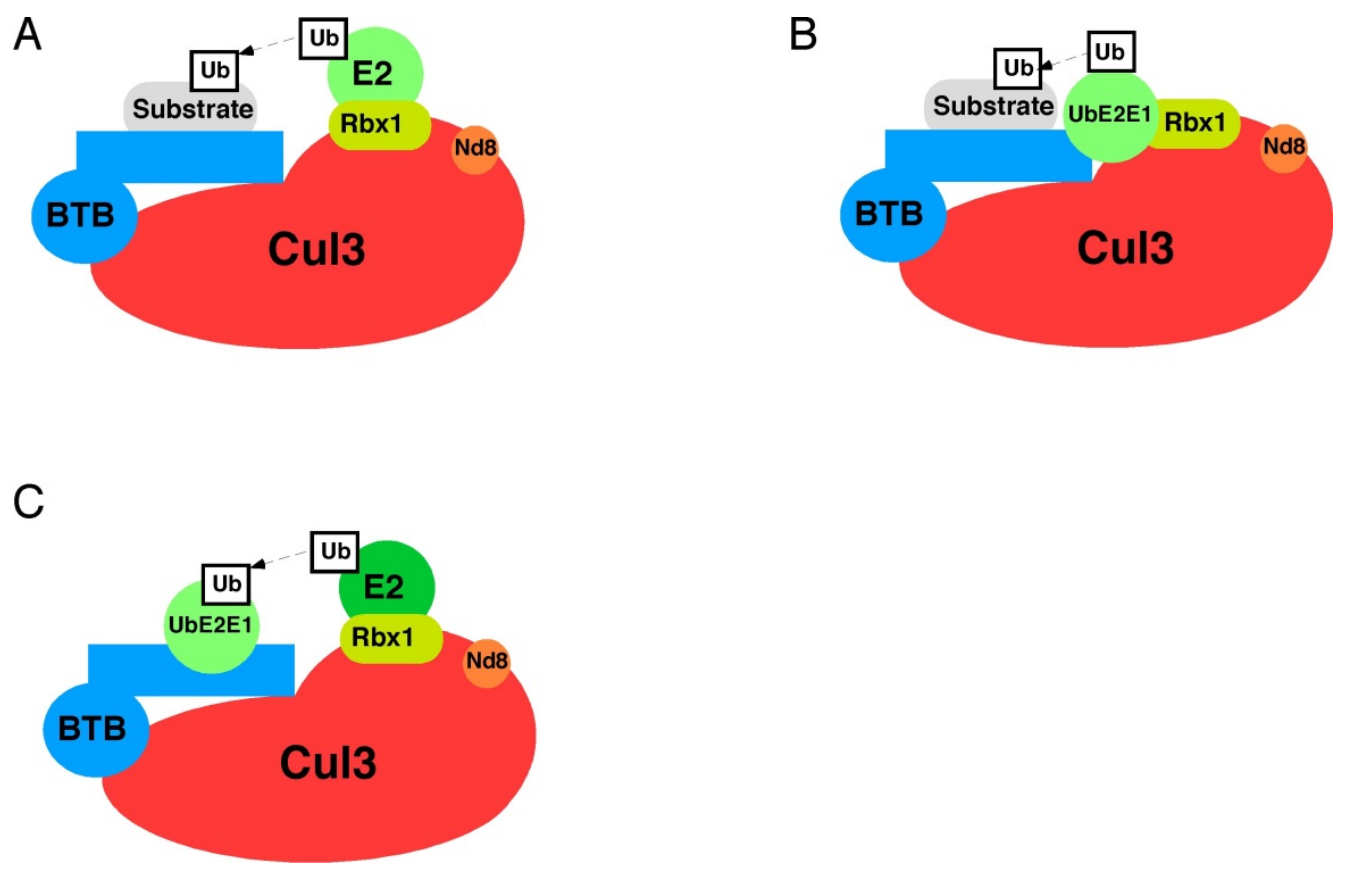

Figure 5.1: Models for UbE2E1 interaction with the Cul3 complex

A) The current model for the assembly of the Cul3 complex. The C- terminus of Cul3 binds the RING protein Rbx1, which serves as a docking site for ubiquitin activated E2 enzymes. An E2 enzyme transfers ubiquitin to Cul3 substrates, which are bound by BTB substrate adapter proteins at the $\mathrm{N}$ - terminus of Cul3. In this study, we observed that the $\mathrm{N}$ - terminus of Cul3 is required for binding E2 enzyme UbE2E1. This observation could be explained by two alternate models shown here. B) One possibility is that BTB substrate adapters are participating in E2 recruitment, and that certain E2s interact with both BTB substrate adapters and Rbx1 to transfer ubiquitin to substrates. C) An alternate possibility is that the E2 UbE2E1 is bound to the Cul3 complex as a substrate, and is ubiquitinated by $\mathrm{Cul} 3$ and a different E2. Future experiments will be performed to further investigate these interactions. 


\section{References}

Angers, S., Thorpe, C.J., Biechele, T.L., Goldenberg, S.J., Zheng, N., MacCoss, M.J., and Moon, R.T. (2006). The KLHL12-Cullin-3 ubiquitin ligase negatively regulates the Wntbeta-catenin pathway by targeting Dishevelled for degradation. Nat Cell Biol 8, 348-357.

Berleth, E.S., and Pickart, C.M. (1996). Mechanism of ubiquitin conjugating enzyme E2230K: catalysis involving a thiol relay? Biochemistry 35, 1664-1671.

Chen, Z.J., Parent, L., and Maniatis, T. (1996). Site-specific phosphorylation of IkappaBalpha by a novel ubiquitination-dependent protein kinase activity. Cell $84,853-$ 862.

Chen, Z.J., and Sun, L.J. (2009). Nonproteolytic functions of ubiquitin in cell signaling. Mol Cell 33, 275-286.

Ciechanover, A., Heller, H., Katz-Etzion, R., and Hershko, A. (1981). Activation of the heat-stable polypeptide of the ATP-dependent proteolytic system. Proc Natl Acad Sci U S A 78, 761-765.

Clurman, B.E., Sheaff, R.J., Thress, K., Groudine, M., and Roberts, J.M. (1996).

Turnover of cyclin $\mathrm{E}$ by the ubiquitin-proteasome pathway is regulated by cdk2 binding and cyclin phosphorylation. Genes Dev 10, 1979-1990.

Cullinan, S.B., Gordan, J.D., Jin, J., Harper, J.W., and Diehl, J.A. (2004). The Keap1BTB protein is an adaptor that bridges $\mathrm{Nrf} 2$ to a Cul3-based E3 ligase: oxidative stress sensing by a Cul3-Keap1 ligase. Mol Cell Biol 24, 8477-8486.

Cummings, C.M., Bentley, C.A., Perdue, S.A., Baas, P.W., and Singer, J.D. (2009). The $\mathrm{Cul3/Klhdc5}$ E3 ligase regulates p60/katanin and is required for normal mitosis in mammalian cells. J Biol Chem 284, 11663-11675.

Duda, D.M., Borg, L.A., Scott, D.C., Hunt, H.W., Hammel, M., and Schulman, B.A. (2008). Structural insights into NEDD8 activation of cullin-RING ligases: conformational control of conjugation. Cell 134, 995-1006.

Dye, B.T., and Schulman, B.A. (2007). Structural mechanisms underlying posttranslational modification by ubiquitin-like proteins. Annu Rev Biophys Biomol Struct 36, 131-150.

Feldman, R.M., Correll, C.C., Kaplan, K.B., and Deshaies, R.J. (1997). A complex of Cdc4p, Skp1p, and Cdc53p/cullin catalyzes ubiquitination of the phosphorylated CDK inhibitor Sic1p. Cell 91, 221-230. 
Furukawa, M., He, Y.J., Borchers, C., and Xiong, Y. (2003). Targeting of protein ubiquitination by BTB-Cullin 3-Roc1 ubiquitin ligases. Nat Cell Biol 5, 1001-1007. Furukawa, M., and Xiong, Y. (2005). BTB protein Keap1 targets antioxidant transcription factor Nrf2 for ubiquitination by the Cullin 3-Roc1 ligase. Mol Cell Biol 25, 162-171.

Ganoth, D., Bornstein, G., Ko, T.K., Larsen, B., Tyers, M., Pagano, M., and Hershko, A. (2001). The cell-cycle regulatory protein Cks1 is required for SCF(Skp2)-mediated ubiquitinylation of p27. Nat Cell Biol 3, 321-324.

Geyer, R., Wee, S., Anderson, S., Yates, J., and Wolf, D.A. (2003). BTB/POZ domain proteins are putative substrate adaptors for cullin 3 ubiquitin ligases. Mol Cell 12, 783 790.

Goebl, M.G., Yochem, J., Jentsch, S., McGrath, J.P., Varshavsky, A., and Byers, B. (1988). The yeast cell cycle gene CDC34 encodes a ubiquitin-conjugating enzyme. Science 241, 1331-1335.

Hershko, A., Ciechanover, A., and Rose, I.A. (1981). Identification of the active amino acid residue of the polypeptide of ATP-dependent protein breakdown. J Biol Chem 256, $1525-1528$.

Hershko, A., Heller, H., Elias, S., and Ciechanover, A. (1983). Components of ubiquitinprotein ligase system. Resolution, affinity purification, and role in protein breakdown. $\mathrm{J}$ Biol Chem 258, 8206-8214.

Hicke, L. (2001). A new ticket for entry into budding vesicles-ubiquitin. Cell 106, 527530 .

Hori, T., Osaka, F., Chiba, T., Miyamoto, C., Okabayashi, K., Shimbara, N., Kato, S., and Tanaka, K. (1999). Covalent modification of all members of human cullin family proteins by NEDD8. Oncogene 18, 6829-6834.

Jin, L., Williamson, A., Banerjee, S., Philipp, I., and Rape, M. (2008). Mechanism of ubiquitin-chain formation by the human anaphase-promoting complex. Cell 133, 653665.

Kamura, T., Koepp, D.M., Conrad, M.N., Skowyra, D., Moreland, R.J., Iliopoulos, O., Lane, W.S., Kaelin, W.G., Jr., Elledge, S.J., Conaway, R.C., et al. (1999). Rbx1, a component of the VHL tumor suppressor complex and SCF ubiquitin ligase. Science 284, 657-661.

Kim, H.T., Kim, K.P., Lledias, F., Kisselev, A.F., Scaglione, K.M., Skowyra, D., Gygi, S.P., and Goldberg, A.L. (2007). Certain pairs of ubiquitin-conjugating enzymes (E2s) 
and ubiquitin-protein ligases (E3s) synthesize nondegradable forked ubiquitin chains containing all possible isopeptide linkages. J Biol Chem 282, 17375-17386.

Kipreos, E.T., Lander, L.E., Wing, J.P., He, W.W., and Hedgecock, E.M. (1996). cul-1 is required for cell cycle exit in $\mathrm{C}$. elegans and identifies a novel gene family. Cell 85, 829839.

Kleiger, G., Hao, B., Mohl, D.A., and Deshaies, R.J. (2009). The acidic tail of the Cdc34 ubiquitin-conjugating enzyme functions in both binding to and catalysis with ubiquitin ligase SCFCdc4. J Biol Chem 284, 36012-36023.

Kobayashi, A., Kang, M.I., Okawa, H., Ohtsuji, M., Zenke, Y., Chiba, T., Igarashi, K., and Yamamoto, M. (2004). Oxidative stress sensor Keapl functions as an adaptor for Cul3-based E3 ligase to regulate proteasomal degradation of Nrf2. Mol Cell Biol 24, 7130-7139.

Kolman, C.J., Toth, J., and Gonda, D.K. (1992). Identification of a portable determinant of cell cycle function within the carboxyl-terminal domain of the yeast CDC34 (UBC3) ubiquitin conjugating (E2) enzyme. Embo J 11, 3081-3090.

Kwon, J.E., La, M., Oh, K.H., Oh, Y.M., Kim, G.R., Seol, J.H., Baek, S.H., Chiba, T., Tanaka, K., Bang, O.S., et al. (2006). BTB domain-containing speckle-type POZ protein (SPOP) serves as an adaptor of Daxx for ubiquitination by Cul3-based ubiquitin ligase. $\mathrm{J}$ Biol Chem 281, 12664-12672.

Lange, S., Perera, S., Teh, P., and Chen, J. Obscurin and KCTD6 regulate cullindependent small ankyrin-1 (sAnk1.5) protein turnover. Mol Biol Cell 23, 2490-2504. Maher, E.R., and Kaelin, W.G., Jr. (1997). von Hippel-Lindau disease. Medicine (Baltimore) 76, 381-391.

Mathias, N., Johnson, S.L., Winey, M., Adams, A.E., Goetsch, L., Pringle, J.R., Byers, B., and Goebl, M.G. (1996). Cdc53p acts in concert with Cdc4p and Cdc34p to control the G1-to-S-phase transition and identifies a conserved family of proteins. Mol Cell Biol 16, 6634-6643.

McEvoy, J.D., Kossatz, U., Malek, N., and Singer, J.D. (2007). Constitutive turnover of cyclin E by Cul3 maintains quiescence. Mol Cell Biol 27, 3651-3666.

Ohh, M., Kim, W.Y., Moslehi, J.J., Chen, Y., Chau, V., Read, M.A., and Kaelin, W.G., Jr. (2002). An intact NEDD8 pathway is required for Cullin-dependent ubiquitylation in mammalian cells. EMBO Rep 3, 177-182.

Ohta, T., Michel, J.J., Schottelius, A.J., and Xiong, Y. (1999). ROC1, a homolog of APC11, represents a family of cullin partners with an associated ubiquitin ligase activity. Mol Cell 3, 535-541. 
Pan, Z.Q., Kentsis, A., Dias, D.C., Yamoah, K., and Wu, K. (2004). Nedd8 on cullin: building an expressway to protein destruction. Oncogene 23, 1985-1997.

Pause, A., Lee, S., Worrell, R.A., Chen, D.Y., Burgess, W.H., Linehan, W.M., and Klausner, R.D. (1997). The von Hippel-Lindau tumor-suppressor gene product forms a stable complex with human CUL-2, a member of the Cdc53 family of proteins. Proc Natl Acad Sci U S A 94, 2156-2161.

Pause, A., Peterson, B., Schaffar, G., Stearman, R., and Klausner, R.D. (1999). Studying interactions of four proteins in the yeast two-hybrid system: structural resemblance of the pVHL/elongin BC/hCUL-2 complex with the ubiquitin ligase complex SKP1/cullin/Fbox protein. Proc Natl Acad Sci U S A 96, 9533-9538.

Pickart, C.M. (2001). Mechanisms underlying ubiquitination. Annu Rev Biochem 70, 503-533.

Pintard, L., Willems, A., and Peter, M. (2004). Cullin-based ubiquitin ligases: Cul3-BTB complexes join the family. Embo J 23, 1681-1687.

Pintard, L., Willis, J.H., Willems, A., Johnson, J.L., Srayko, M., Kurz, T., Glaser, S., Mains, P.E., Tyers, M., Bowerman, B., et al. (2003). The BTB protein MEL-26 is a substrate-specific adaptor of the CUL-3 ubiquitin-ligase. Nature 425, 311-316.

Plafker, K.S., Nguyen, L., Barneche, M., Mirza, S., Crawford, D., and Plafker, S.M. The ubiquitin-conjugating enzyme UbcM2 can regulate the stability and activity of the antioxidant transcription factor Nrf2. J Biol Chem 285, 23064-23074.

Plafker, K.S., Singer, J.D., and Plafker, S.M. (2009). The ubiquitin conjugating enzyme, UbcM2, engages in novel interactions with components of cullin-3 based E3 ligases.

Biochemistry 48, 3527-3537.

Salinas, G.D., Blair, L.A., Needleman, L.A., Gonzales, J.D., Chen, Y., Li, M., Singer, J.D., and Marshall, J. (2006). Actinfilin is a Cul3 substrate adaptor, linking GluR6 kainate receptor subunits to the ubiquitin-proteasome pathway. J Biol Chem 281, 4016440173.

Sarkari, F., Wheaton, K., La Delfa, A., Mohamed, M., Shaikh, F., Khatun, R., Arrowsmith, C.H., Frappier, L., Saridakis, V., and Sheng, Y. Ubiquitin-specific protease 7 is a regulator of ubiquitin-conjugating enzyme UbE2E1. J Biol Chem 288, 1697516985.

Saville, M.K., Sparks, A., Xirodimas, D.P., Wardrop, J., Stevenson, L.F., Bourdon, J.C., Woods, Y.L., and Lane, D.P. (2004). Regulation of p53 by the ubiquitin-conjugating enzymes UbcH5B/C in vivo. J Biol Chem 279, 42169-42181. 
Seol, J.H., Feldman, R.M., Zachariae, W., Shevchenko, A., Correll, C.C., Lyapina, S., Chi, Y., Galova, M., Claypool, J., Sandmeyer, S., et al. (1999). Cdc53/cullin and the essential Hrt1 RING-H2 subunit of SCF define a ubiquitin ligase module that activates the E2 enzyme Cdc34. Genes Dev 13, 1614-1626.

Shibata, S., Zhang, J., Puthumana, J., Stone, K.L., and Lifton, R.P. Kelch-like 3 and Cullin 3 regulate electrolyte homeostasis via ubiquitination and degradation of WNK4. Proc Natl Acad Sci U S A 110, 7838-7843.

Silver, E.T., Gwozd, T.J., Ptak, C., Goebl, M., and Ellison, M.J. (1992). A chimeric ubiquitin conjugating enzyme that combines the cell cycle properties of CDC34 (UBC3) and the DNA repair properties of RAD6 (UBC2): implications for the structure, function and evolution of the E2s. Embo J 11, 3091-3098.

Singer, J.D., Gurian-West, M., Clurman, B., and Roberts, J.M. (1999). Cullin-3 targets cyclin $\mathrm{E}$ for ubiquitination and controls $\mathrm{S}$ phase in mammalian cells. Genes Dev 13, 2375-2387.

Skaar, J.R., D'Angiolella, V., Pagan, J.K., and Pagano, M. (2009). SnapShot: F Box Proteins II. Cell 137, 1358, 1358 e1351.

Skowyra, D., Craig, K.L., Tyers, M., Elledge, S.J., and Harper, J.W. (1997). F-box proteins are receptors that recruit phosphorylated substrates to the SCF ubiquitin-ligase complex. Cell 91, 209-219.

Stebbins, C.E., Kaelin, W.G., Jr., and Pavletich, N.P. (1999). Structure of the VHLElonginC-ElonginB complex: implications for VHL tumor suppressor function. Science $284,455-461$.

Stogios, P.J., Downs, G.S., Jauhal, J.J., Nandra, S.K., and Prive, G.G. (2005). Sequence and structural analysis of BTB domain proteins. Genome Biol 6, R82.

Summers, M.K., Pan, B., Mukhyala, K., and Jackson, P.K. (2008). The unique N terminus of the UbcH10 E2 enzyme controls the threshold for APC activation and enhances checkpoint regulation of the APC. Mol Cell 31, 544-556.

Tan, P., Fuchs, S.Y., Chen, A., Wu, K., Gomez, C., Ronai, Z., and Pan, Z.Q. (1999). Recruitment of a ROC1-CUL1 ubiquitin ligase by Skp1 and HOS to catalyze the ubiquitination of I kappa B alpha. Mol Cell 3, 527-533.

Verma, R., Feldman, R.M., and Deshaies, R.J. (1997). SIC1 is ubiquitinated in vitro by a pathway that requires $\mathrm{CDC} 4, \mathrm{CDC} 34$, and cyclin/CDK activities. Mol Biol Cell 8, 14271437.

Willems, A.R., Schwab, M., and Tyers, M. (2004). A hitchhiker's guide to the cullin ubiquitin ligases: SCF and its kin. Biochim Biophys Acta 1695, 133-170. 
Xie, C., Powell, C., Yao, M., Wu, J., and Dong, Q. Ubiquitin-conjugating enzyme E2C: a potential cancer biomarker. Int J Biochem Cell Biol 47, 113-117.

Xu, L., Wei, Y., Reboul, J., Vaglio, P., Shin, T.H., Vidal, M., Elledge, S.J., and Harper, J.W. (2003). BTB proteins are substrate-specific adaptors in an SCF-like modular ubiquitin ligase containing CUL-3. Nature 425, 316-321.

Yamoah, K., Oashi, T., Sarikas, A., Gazdoiu, S., Osman, R., and Pan, Z.Q. (2008). Autoinhibitory regulation of SCF-mediated ubiquitination by human cullin 1's C-terminal tail. Proc Natl Acad Sci U S A 105, 12230-12235.

Ye, Y., and Rape, M. (2009). Building ubiquitin chains: E2 enzymes at work. Nat Rev Mol Cell Biol 10, 755-764.

Yu, Z.K., Gervais, J.L., and Zhang, H. (1998). Human CUL-1 associates with the SKP1/SKP2 complex and regulates p21(CIP1/WAF1) and cyclin D proteins. Proc Natl Acad Sci U S A 95, 11324-11329.

Zhang, D.D., Lo, S.C., Cross, J.V., Templeton, D.J., and Hannink, M. (2004). Keap1 is a redox-regulated substrate adaptor protein for a $\mathrm{Cul3}$-dependent ubiquitin ligase complex. Mol Cell Biol 24, 10941-10953.

Zhang, D.D., Lo, S.C., Sun, Z., Habib, G.M., Lieberman, M.W., and Hannink, M. (2005). Ubiquitination of Keap1, a BTB-Kelch substrate adaptor protein for Cul3, targets Keap1 for degradation by a proteasome-independent pathway. J Biol Chem 280, 30091-30099. Zheng, N., Schulman, B.A., Song, L., Miller, J.J., Jeffrey, P.D., Wang, P., Chu, C., Koepp, D.M., Elledge, S.J., Pagano, M., et al. (2002). Structure of the Cul1-Rbx1-Skp1-F boxSkp2 SCF ubiquitin ligase complex. Nature 416, 703-709.

Zollman, S., Godt, D., Prive, G.G., Couderc, J.L., and Laski, F.A. (1994). The BTB domain, found primarily in zinc finger proteins, defines an evolutionarily conserved family that includes several developmentally regulated genes in Drosophila. Proc Natl Acad Sci U S A 91, 10717-10721. 